\title{
Chitin Synthases Are Critical for Reproduction, Molting, and Digestion in the Salmon Louse (Lepeophtheirus salmonis)
}

\author{
Hulda María Harðardóttir ${ }^{1}{ }^{*}$, Rune Male ${ }^{1}$, Frank Nilsen ${ }^{1}$ and Sussie Dalvin ${ }^{2}$ D \\ 1 Sea Lice Research Centre, Department of Biological Sciences, University of Bergen, P.O. Box 7803, \\ N-5020 Bergen, Norway; rune.male@uib.no (R.M.); frank.nilsen@uib.no (F.N.) \\ 2 Sea Lice Research Centre, Institute of Marine Research, P.O. Box 1870, Nordnes, N-5817 Bergen, Norway; \\ sussie.dalvin@hi.no \\ * Correspondence: hulda.hardardottir@uib.no
}

Citation: Harðardóttir, H.M.; Male,

R.; Nilsen, F.; Dalvin, S. Chitin

Synthases Are Critical for

Reproduction, Molting, and Digestion in the Salmon Louse (Lepeophtheirus salmonis). Life 2021, 11, 47. https:// doi.org/10.3390/life11010047

Received: 12 November 2020 Accepted: 11 January 2021 Published: 13 January 2021

Publisher's Note: MDPI stays neutral with regard to jurisdictional clai$\mathrm{ms}$ in published maps and institutional affiliations.

Copyright: $(\odot 2021$ by the authors. Licensee MDPI, Basel, Switzerland. This article is an open access article distributed under the terms and conditions of the Creative Commons Attribution (CC BY) license (https:// creativecommons.org/licenses/by/ $4.0 /)$.

\begin{abstract}
Chitin synthase (CHS) is a large transmembrane enzyme that polymerizes Uridine diphosphate $\mathrm{N}$-acetylglucosamine into chitin. The genomes of insects often encode two chitin synthases, CHS1 and CHS2. Their functional roles have been investigated in several insects: CHS1 is mainly responsible for synthesizing chitin in the cuticle and CHS2 in the midgut. Lepeophtheirus salmonis is an ectoparasitic copepod on salmonid fish, which causes significant economic losses in aquaculture. In the present study, the tissue-specific localization, expression, and functional role of L. salmonis chitin synthases, LsCHS1 and LsCHS2, were investigated. The expressions of LsCHS1 and LsCHS2 were found in oocytes, ovaries, intestine, and integument. Wheat germ agglutinin (WGA) chitin staining signals were detected in ovaries, oocytes, intestine, cuticle, and intestine in adult female L. salmonis. The functional roles of the LsCHSs were investigated using RNA interference (RNAi) to silence the expression of LsCHS1 and LsCHS2. Knockdown of LsCHS1 in pre-adult I lice resulted in lethal phenotypes with cuticle deformation and deformation of ovaries and oocytes in adult lice. RNAi knockdown of LsCHS2 in adult female L. salmonis affected digestion, damaged the gut microvilli, reduced muscular tissues around the gut, and affected offspring. The results demonstrate that both LsCHS1 and LsCHS2 are important for the survival and reproduction in L. salmonis.
\end{abstract}

Keywords: chitin; double-stranded RNA; in situ hybridization; sea lice; aquaculture; ecdysis

\section{Introduction}

The salmon louse, Lepeophtheirus salmonis, a parasitic copepod on salmonid fish, is the most commonly found fish louse on salmonids in the Atlantic Ocean [1]. The parasite feeds on host blood, mucus, and skin [2], causing multiple health problems to the host [3-6]. The salmon louse is an economically important pest in salmon farming and a challenge to the salmon farming industry because of a lack of effective methods to handle the parasite $[7,8]$. Salmon lice produced on farmed fish spread to wild fish and pose an ecological challenge [9-11].

The life cycle of L. salmonis consists of eight stages, each separated by a molt [12]. The first three stages (nauplius I and II, and copepodid) are planktonic. The copepodid is the infective stage and becomes parasitic after attachment to a host. The last five life stages (chalimus I and II, pre-adult I and II, and adult stage) are parasitic. The final and last molt is to the adult stage, after which the female undergoes additional growth in the genital segment and abdomen, defined in six maturition stages (T1-T6), during which reproduction is initiated [13]. The oocytes are produced in the ovaries positioned in the cephalothorax and enter the oviduct as previtellogenic oocytes. Vitellogenesis takes place as oocytes enter the genital segment [14]. Males attach spermatophores to the posterior end of the genital segment of females, and eggs are fertilized externally as they are extruded from the genital segment. 
Attempts to control L. salmonis with anti-sea louse medicines have resulted in emerging resistances [8]; therefore, new tools are needed to control L. salmonis infections. These could be medicines targeting processes in L. salmonis, which are absent or different in other relevant species. As molting and the formation of an exoskeleton are unique to invertebrates, they are attractive targets for new treatments.

Chitin, a polysaccharide of $N$-acetylglucosamine, is a structural building block of the exoskeleton of arthropods and is synthesized by the enzyme chitin synthase (CHS). Chitin is also present in the peritrophic matrix, a protective layer covering the microvilli of the gut [15-17]. L. salmonis has a chitin layer in the foregut and hindgut, but not the midgut. Similar to many hemipteran insects the peritrophic matrix has not been found in the midgut $[18,19]$. Chitin has also been reported in the ovaries, oocytes, embryonic cuticle, and eggs in insects $[20,21]$.

Benzoylureas, also referred to as chitin synthase inhibitors (CSIs), are used to control pests. In Atlantic salmon farming, CSIs are used to control L. salmonis and are administered through feeding or bath treatments. In Norway, diflubenzuron and teflubenzuron are the two benzoylureas used in salmon farming. Because these chemicals can harm non-target species in the marine environment, drug use is limited [22]. Chitin has also been reported in aquatic vertebrates, which may also be affected by CSIs [23,24]. Nevertheless, damage to farmed fish caused by CSI treatments has not been reported to our knowledge. The mode of action of this class of drugs is interesting as resistance has never been reported in L. salmonis despite many years of use. The mode of action of benzoylurea is not fully understood. Mutation in the chs1 gene, which changes isoleucine to methionine, leucine, or phenylalanine, was first reported in several strains of a benzoylurea-resistant moth, Plutella xylostella, and later documented in benzoylurea-resistant mosquitoes, Culex pipiens [25-27]. This mutation is positioned in a conserved sequence located in the transmembrane domain, thought to be the translocation site for chitin polymers across the membrane. Furthermore, using the genome-editing method clustered regularly interspaced short palindromic repeats (CRISPR)/Cas9, the mutations were introduced into Drosophila melanogaster and conferred significant resistance towards CSIs [25].

Many insects have two CHS gene variants, named CHS1 and CHS2. CHS1 synthesizes chitin in the integument, while CHS2 synthesizes chitin in the peritrophic matrix [28-30]. Gene encoding CHS2 has not been found in the hemipteran insect genome, which are also characterized by the absence of the peritrophic matrix. Instead, they have a perimicrovillar membrane: An extracellular layer with a similar function to the peritrophic matrix [21,31]. In decapods, only one type of CHS is reported [32], while for the copepod Tigriopus japonicus, three CHSs have been found: One CHS1 and two types of CHS2 [33]. Like insects, L. salmonis have two copies of CHS, which have been classified to LsCHS1 and LsCHS2 based on their protein sequences [34]. The tissue-specific expression and exact functional role of these two LsCHSs are not known. In a recent study, knockdown of LsCHSs using RNA interference (RNAi) in L. salmonis larvae resulted in aberrant and lethal phenotypes when knocking down LsCHS1, while LsCHS2 knockdown had no measurable effect [35]. RNAi-mediated gene silencing in insects has shown that CHS is required for development, growth, reproduction, and digestion [20,21,36,37]. More understanding of CHS can lead to medicine development more specifically directed at salmon louse enzymes.

The present study aimed to enhance the understanding of the role of CHSs during the development and reproduction in L. salmonis. Here the expression of L. salmonis CHS1 and CHS2 was analyzed in diverse tissues from adult female lice. Furthermore, their transcriptional location by in situ hybridization was determined in adult female lice. Finally, their functional roles in the parasitic stages of L. salmonis was obtained by RNAi-mediated gene silencing approach. 


\section{Materials and Methods}

\subsection{Lepeophtheirus salmonis Production}

A laboratory strain (LsGulen) of salmon louse (Lepeophtheirus salmonis) was propagated on Atlantic salmon (Salmo salar) [38]. The salmon were hand fed on a commercial diet and kept in seawater in standard conditions: A salinity of $34.5 \mathrm{ppt}$ with a temperature of $10^{\circ} \mathrm{C}$. Salmon lice were collected from infected Atlantic salmon anesthetized with a mixture of benzocaine $(60 \mathrm{mg} / \mathrm{L})$ and methomidate $(5 \mathrm{mg} / \mathrm{L})$ for $3 \mathrm{~min}$. All experiments were done according to the Norwegian Animal Welfare Legislations and the Animal Ethics Committee of the Norwegian Food Safety Authority (ID8589). The fish are not expected to have any adverse effects from the low level of $L$. salmonis infections.

\subsection{RNA Interference (RNAi) Experiment}

\subsubsection{Synthesis of dsRNA}

Double-stranded RNA (dsRNA) fragments for LsCHS1 (NCBI GenBank ID MH350851, Ensembl Metazoa EMLSAG00000002853), LsCHS2 (MH350853, EMLSAG00000007308), and the negative control cod trypsin $(C P Y 185)$ were produced using the MEGAscripts ${ }^{\circledR}$ RNAi Kit (Ambion, Austin, TX, USA) according to the supplier's instructions with the primers listed in Table 1. Complementary DNA (cDNA) from pre-adult II (for LsCHS1) or adult females (for LsCHS2) were used as templates for PCR production to synthesize the dsRNA fragments. For the negative control, the PCR product was generated from a plasmid containing the cod trypsin (CPY185) fragment. The control fragment has no significant similarity to transcripts expressed in L. salmonis [39]. The final concentration of dsRNA was measured using spectrometry (Nanodrop Technologies Inc., Wilmington, DE, USA). The dsRNA fragments were $174 \mathrm{bp}$ long for LsCHS1, $564 \mathrm{bp}$ long for LsCHS2, and 800 bp for CPY185.

\subsubsection{Injection of dsRNA Fragments into Pre-Adult I Lepeophtheirus salmonis}

For the injections, the dsRNA solutions were diluted to $600 \mathrm{ng} / \mu \mathrm{L}$, and a drop of bromophenol blue (approximately $20 \mu \mathrm{L}$ ) was added to control the injection success visually [39]. The experiments were performed in pre-adult I lice to follow the development to adults. On the first day of the RNAi experiments, the lice were carefully removed from the host fish using tweezers. The dsRNA (approximately $0.5 \mu \mathrm{L}$ ) was injected into the cephalothorax of each louse using borosilicate glass capillaries and pressure from a mouth tube. After the injection, the lice were incubated in seawater for a few hours to recover and then returned to the host fish.

\subsubsection{RNAi Trials}

Four RNAi experiments were performed, two in males and two in females for both genes (LsCHS1 and LsCHS2) (Figure 1). Trial 1: Males were injected with either dsLsCHS1 or dsLsCHS2 to analyze the phenotypic effects on the transcriptional knockdown. Trial 2: Males were injected with either dsLsCHS1 or dsLsCHS2 and used for histological analysis. For dsLsCHS1, males were harvested in the pre-adult II stage. For dsLsCHS2, adult males were harvested. Trial 3: Females were injected with either dsLsCHS1 or dsLsCHS2 to analyze the phenotypic effects on the transcriptional knockdown. The knockdown effects on phenotype were analyzed in pre-adult II females, and dsLsCHS2-injected adult female lice were collected for histological analysis. Trial 4: Females were injected with dsLsCHS1 or dsLsCHS2 and sampled for histological analysis. For LsCHS1, pre-molt pre-adult or maturing adult females were harvested. For LsCHS2, adult females with the second pair of egg strings were harvested. 
Table 1. List of primer sequences used for quantitative RT-PCR (qPCR) assay, in situ hybridization, and RNA interference (RNAi) approach.

\begin{tabular}{|c|c|c|c|c|c|}
\hline Gene & Primer Identification & Forward $\left(3^{\prime}-5^{\prime}\right)$ & Reverse $\left(3^{\prime}-5^{\prime}\right)$ & Method & Product Size \\
\hline \multirow[t]{4}{*}{ LsCHS1 } & $\begin{array}{l}\text { Forward_b2874 } \\
\text { Reverse_b2875 }\end{array}$ & GCGTTGCGTTCATACCTTCT & TAATTTTCCCACCAACCCGC & qPCR & 214 \\
\hline & $\begin{array}{l}\text { Forward_b4615 } \\
\text { Reverse_b4614 }\end{array}$ & $\begin{array}{l}\text { TAATACGACTCACTATAGGGAGA- } \\
\text { AGCCTGGACCGTACCTGTAT }\end{array}$ & CGGTGCCAAACGTTCACAAT & $\begin{array}{l}\text { In situ } \\
\text { anit-sense probe }\end{array}$ & 721 \\
\hline & $\begin{array}{l}\text { Forward_b4613 } \\
\text { Reverse_b4616 }\end{array}$ & AGCCTGGACCGTACCTGTAT & $\begin{array}{l}\text { TAATACGACTCACTATAGGGAGA- } \\
\text { CGGTGCCAAACGTTCACAAT }\end{array}$ & $\begin{array}{c}\text { In situ } \\
\text { sense probe }\end{array}$ & 721 \\
\hline & $\begin{array}{l}\text { Forward_b4611 } \\
\text { Reverse_b4612 }\end{array}$ & $\begin{array}{l}\text { TAATACGACTCACTATAGGGAGA- } \\
\text { TGGTGTGAGGCGTTAGAACC }\end{array}$ & $\begin{array}{l}\text { TAATACGACTCACTATAGGGAGA- } \\
\text { CGTGAGTGGAGTGGCTTCAT }\end{array}$ & dsRNA & 380 \\
\hline Gene & Primer Identification & Forward $\left(3^{\prime}-5^{\prime}\right)$ & Reverse $\left(3^{\prime}-5^{\prime}\right)$ & Method & Product Size \\
\hline \multirow[t]{3}{*}{ LsCHS2 } & $\begin{array}{l}\text { Forward b2876 } \\
\text { Reverse b2877 }\end{array}$ & TCACTCACGTCCCCATTTCT & TCGATGGATGCTAGCCGAAT & qPCR & 242 \\
\hline & $\begin{array}{l}\text { Forward_b7044 } \\
\text { Reverse_b5763 }\end{array}$ & CTTGGACACTTCCTTTAGGC & $\begin{array}{l}\text { TAATACGACTCACTATAGGGAGA- } \\
\text { GACCGCTGCATAAGATACG }\end{array}$ & $\begin{array}{l}\text { In situ } \\
\text { anti-sense probe }\end{array}$ & 551 \\
\hline & $\begin{array}{l}\text { Forward_b5762 } \\
\text { Reverse_b7045 }\end{array}$ & $\begin{array}{l}\text { TAATACGACTCACTATAGGGAGA- } \\
\text { CTTGGACACTTCCTTTAGGC }\end{array}$ & GACCGCTGCATAAGATACG & $\begin{array}{l}\text { In situ } \\
\text { sense probe }\end{array}$ & 551 \\
\hline
\end{tabular}




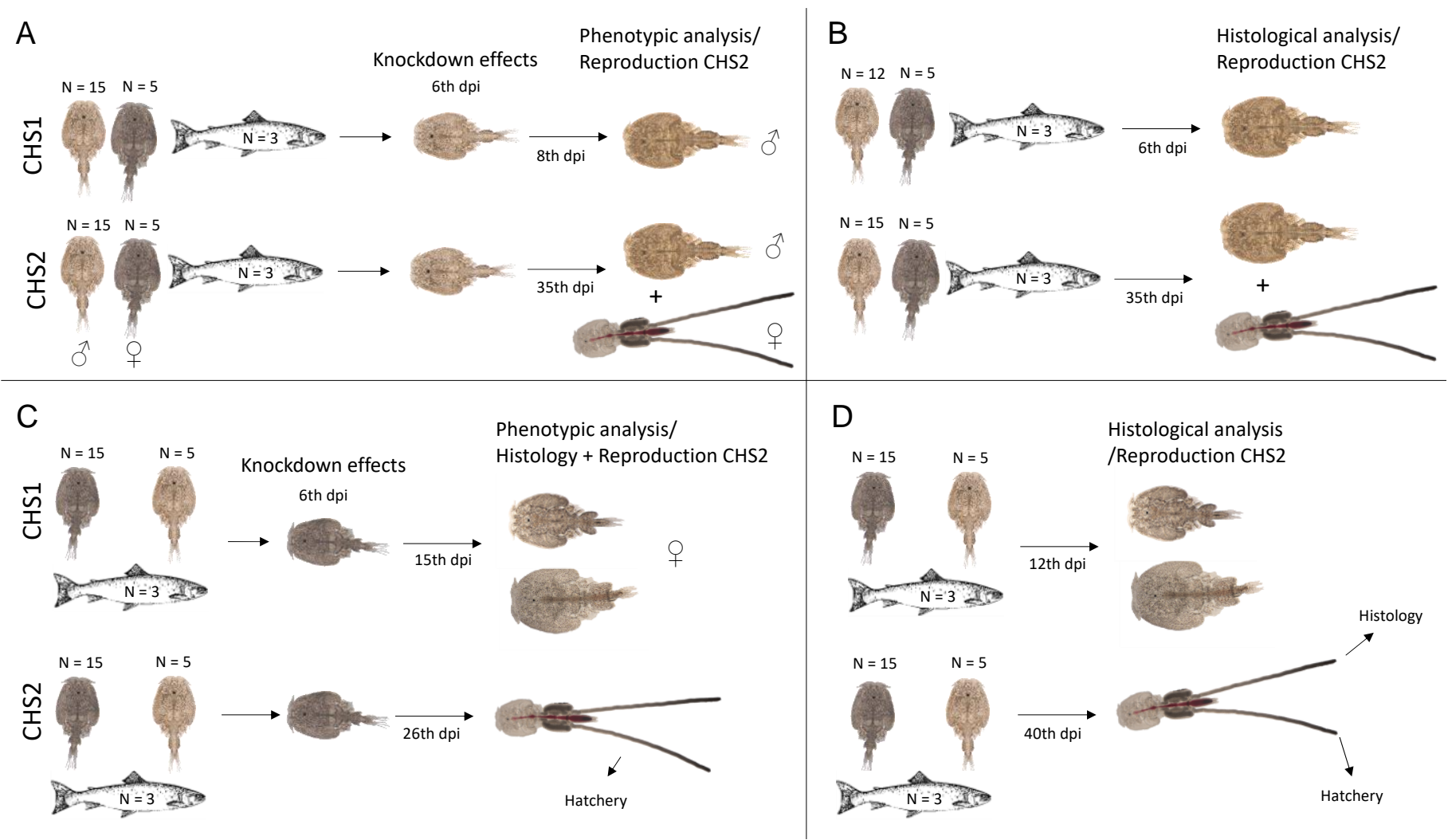

Figure 1. Illustration of the study setup. Trial 1 (A) and trial 2 (B) are males subjected to RNAi knockdown. Trial 3 (C) and trial 4 (D) are females subjected to RNAi knockdown. Knockdown of LsCHS1 (above) and LsCHS2 (below) for each trial. $(A, C)$ The first arrows indicate when the knockdown analyses were performed and the second demonstrate the total number of days the lice stayed on the fish before termination. (A,B) Female with egg strings, reproduction success was studied in females placed with LsCHS2 knockdown males. (C,D) Female with egg strings, reproductive success was analyzed in LsCHS2 knockdown females. LsCHS1 and LsCHS2 knockdown lice were terminated as pre-adult II or unmatured adults and mature adults, respectively. Days post-injection $=\mathrm{dpi}$.

\subsubsection{Fish Tank Setup}

The experiments were performed in standard conditions (Section 2.1) using fish tanks. For trials 1,3 , and 4 , fish were placed in small fish tanks $\left(0.07 \mathrm{~m}^{3}\right)$, one fish in each tank. Three fish were used for each dsRNA group, and each fish carried ten to 15 injected lice together with five non-injected lice of the opposite sex. For trial 2: Larger fish tanks $\left(0.5 \mathrm{~m}^{3}\right)$ were used with five salmon in each. One tank was used for each dsRNA fragment, and each fish carried 12 injected males and five non-injected female lice. Fish tanks were equipped with suitable aquarium nets to collect lice from the water outlet. The lice that fell off the fish and were caught in the net were collected and photographed, and behavioral responses such as swimming and grabbing ability were analyzed. If the lice were normal looking, they were released back into the seawater in the same fish tank. Performing RNAi-mediated knockdown in parasitic stages of L. salmonis in fish tanks will lead to small losses of both experimental and control lice due to the natural behavior of the lice. Most of the lice will end up in the net with the water outlet, whilst others are possibly eaten by the fish, or become stuck inside the tank during the experiment. Therefore, fish infected with lice injected with the same dsRNA were placed vertically. Because the water flow goes from top to bottom, any lice that evade the net and fall into the water outlet will end up in a fish tank with lice injected with the same dsRNA. 


\subsubsection{Sampling and Termination of Trials}

The transcriptional levels of target genes (LsCHS1 or LsCHS2) were measured in preadult II lice using qPCR (see Section 2.5) to determine the silencing efficiency of dsRNA. For trials 1 and 3: Pre-adult II lice injected with dsLsCHS2, dsLsCHS2, or dsCPY were sampled from fish on the sixth day post-injection. At the end of the experiments, all lice were collected from the host fish and photographed using a Canon EOS 600D camera attached with an adapter (Lmscope) to an Olympus SZX9 dissecting microscope. Subsequently, the lice were fixed in $4 \%$ paraformaldehyde or Karnovsky fixative for histological analysis (see Sections 2.6 and 2.7). The termination points were adjusted for each trial because of the different knockdown effects on the phenotype between LsCHS1 and LsCHS2. For dsLsCHS1, trials 1 and 2 were terminated on the eight- and sixth-day post-injection, respectively. Trials 3 and 4 were terminated 13- and 15-days post-injection, respectively. For dsLsCHS2, trial 1 and 2 were terminated 35-days post-injection when the dsRNA-injected male lice were adults, and the females had produced the second pair of egg strings. For trial 3, the experiment was terminated 26-days post-injection when the female had produced the first set of egg strings. Trial 4 was terminated 40-days post-injection when the females had produced the second set of egg strings. In trials 1 and 2, both egg strings were removed from untreated adult females and collected into flow-through incubators. In trials 3 and 4 , pairs of egg strings were collected from each adult dsRNA-treated female. One egg string was placed into a flow-through incubator, and the other was fixed in $4 \%$ paraformaldehyde for histological analysis (see Section 2.7). Hatching ability and the development of the larvae into copepodids were documented. In trials 3 and 4, the total length of the lice was measured. The total length and the morphology of the genital segment were used to determine the life stage of the dsLsCHS1-injected lice. For LsCHS2 knockdown experiments, the total length of the adult females and their egg strings were measured in both the experimental and control groups. The possibility of LsCHS knockdown off-target effects was not investigated.

\subsection{Collection of Tissues and Organs for Tissue-Specific Localization of Transcripts}

For tissue-specific gene expression analysis, the organs and tissues were dissected from adult $L$. salmonis females. The body was separated between the cephalothorax and genital segment using a scalpel, and the dorsal integument was carefully stripped from the cephalothorax using tweezers. Then the ovaries were carefully removed from the remaining cephalothorax tissues. Subsequently, the integument covering the genital segment was opened, and the secondary oocytes (hereafter referred to as oocytes) were extracted together with the cement glands. The cement glands were removed from the oocytes using two tweezers: One to separate the oocytes from the cement glands, and the other to remove the cement glands. The intestine was extracted from a new louse. First, the dorsal integument of the cephalothorax was removed, and the genital segment was opened as described above. Intestinal tissue was then removed using tweezers and a scalpel to cut away the tissues attached to the intestine. The tissues around the eye were cut away to get the intestine free from the cephalothorax. The intestine inside the abdomen (the most posterior part of the louse) was collected by cutting away the tissues on both sides of the intestine. The remaining tissues around the intestine were scraped away with tweezers and a scalpel.

\subsection{RNA Purification and $c D N A$ Synthesis}

RNA was extracted from whole lice (pre-adult and adult), egg string pairs, and extracted samples (integument, intestine, and oocytes) from female lice using a Tri Reagent ${ }^{\circledR}$ protocol (Sigma-Aldrich, St. Louis, MO, USA). For homogenization, the lice and tissues (except ovaries, see below) were collected into Eppendorf tubes together with $5 \mathrm{~mm}$ stainless steel beads and Trizol (Sigma-Aldrich, St. Louis, MO, USA, $1 \mathrm{~mL}$ ). The samples were homogenized for $2 \mathrm{~min}$ in a TissueLyser II (Qiagen, Hilden, Germany) at a frequency of $30 \mathrm{~Hz}$. The RNA isolation was done according to a Tri Reagent ${ }^{\circledR}$ protocol (Sigma-Aldrich) using $0.2 \mathrm{~mL}$ chloroform (Sigma-Aldrich, St. Louis, MO, USA) and the RNA pellets were 
washed twice in $1 \mathrm{~mL} \mathrm{75 \%}$ ethanol and dissolved in $15 \mu \mathrm{L}$ of RNAase-free water. The RNA samples were analyzed using Nanodrop 2000 spectrophotometry (Nanodrop Products, Wilmington, Germany) and stored at $-80^{\circ} \mathrm{C}$ or directly treated with DNase. The DNase treatment was performed according to the manufacturer's protocol (Turbo DNase free ${ }^{\mathrm{TM}}$ kit, Ambion Foster City, CA, USA). The ovaries (three in each sample) were purified using the RNeasy Micro Kit (Qiagen, Hilden, Germany) according to the manufacturer's recommendations using $1.4 \mathrm{~mm}$ zirconium oxide beads to homogenize the samples. The purified RNA was stored at $-80^{\circ} \mathrm{C}$ before complementary DNA (cDNA) synthesis. For all samples, RNA (200 ng) was reverse transcribed to cDNA using the Affinity Script cDNA Kit for qPCR (Agilent, San Clara, CA, USA) according to the manufacturer's instructions. The cDNA samples were diluted ten times in RNAase-free water and stored at $-20{ }^{\circ} \mathrm{C}$ until qPCR analysis.

\subsection{Quantitative RT-PCR ( $q P C R$ )}

The transcriptional levels of LsCHS1 and LsCHS2 were quantified by qPCR using PowerUp ${ }^{\mathrm{TM}}$ SYBR Green Fast Universal PCR Master Mix (Thermo Fisher Scientific, Waltham, MA, USA). The qPCR analysis was performed using the same qPCR primers as described in a previous study using the same qPCR primers [34]. Here, the primers are listed in Table 1. The salmon louse elongation factor $1 \alpha(\mathrm{eEF} 1 \alpha)$, adenine nucleotide translocator 3 (ADT3), and $18 \mathrm{~S}$ were used as the reference genes $[40,41]$. Reaction specificity was verified by the presence of a single peak in the melting curve. For each experiment, three to five biological replicates (three for ovaries, four for integument, intestine, oocytes, and eggs, and five for knockdown samples) were analyzed, each with two technical replicates. One sample without reverse transcriptase enzymes was included to detect possible contamination by genomic DNA. Thermal cycling and quantification were done on the Applied Biosystems 7500 Fast Real-Time PCR System in $10 \mu \mathrm{L}$ reactions under standard conditions (initiation: $50{ }^{\circ} \mathrm{C}$ for $2 \mathrm{~min}$, holding at $95^{\circ} \mathrm{C}$ for $2 \mathrm{~min}, 40$ cycles at $95^{\circ} \mathrm{C}$ for $15 \mathrm{~s}$ then $60{ }^{\circ} \mathrm{C}$ for $1 \mathrm{~min}$ ). The relative quantification analysis was performed using the $2^{-\Delta \mathrm{Ct}}$ method by calculating the difference in threshold cycles $(\mathrm{Ct})$ between the gene of interest and the average $\mathrm{Ct}$ values of the reference genes [42].

\subsection{Histology}

L. salmonis were fixed in Karnovsky fixative with $4 \%$ sucrose overnight at $4{ }^{\circ} \mathrm{C}$. Thereafter, lice were washed twice in 1\% PBS, dehydrated once in 75\% ethanol, and twice in $96 \%$ ethanol for $15 \mathrm{~min}$. They were then pre-infiltrated with Technovit 7100/ethanol (50/50) for two hours (Technovit 7100, Kulzer, Heraeus, Germany) and infiltrated with Technovit $7100 /$ hardener overnight before embedding in plastic. The embedded lice were cut into $2 \mu \mathrm{m}$ thick sections, then dried at $50{ }^{\circ} \mathrm{C}$ before they were stained with toluidine blue $(1 \%$ toluidine blue in $2 \%$ borax). The slides were stained for $30 \mathrm{~s}$ in the staining solution, then washed in running tap water. The stained sections were mounted with DPX New Mounting Medium (Merck, Darmstadt, Germany). Photos were taken using a Zeiss Axicam 105 color (Zeiss) camera attached to a Zeiss Axio Scope.A1 (Zeiss) microscope.

\subsection{Paraffin Embedding}

Lice were paraffin embedded for in situ hybridization (see Section 2.8) and immunohistochemistry analysis (see Section 2.9). Pre-adult II and adult females were incubated in $4 \%$ paraformaldehyde diluted in phosphate-buffered saline (PBS) overnight. The next day, the lice were washed once with 1\% PBS, then incubated in 1\% PBS for $30 \mathrm{~min}$, and subsequently kept in $70 \%$ ethanol at $4{ }^{\circ} \mathrm{C}$ for at least one day before paraffin embedding in a Histokinette (Histokinette 2000, Reichert-Jung GmbH, Nussloch, Germany). Here, the samples were washed in PBS, dehydrated through a graded ethanol series, and embedded in paraffin. The sections were cut into $5 \mu \mathrm{m}$ thick slides using a Leica RM 225 microtome (Leica Microsystems, Wetzlar, Germany). 


\subsection{In Situ Hybridization Analysis}

The in situ hybridization was performed as described earlier in [43] using a digoxigenin (DIG)-labeled kit (Roche, Basel, Switzerland) with the following modification: Proteinase K treatment was increased to $20 \mathrm{~min}$. Anti-sense and sense probes of $721 \mathrm{bp}$ (LsCHS1) and $551 \mathrm{bp}$ (LsCHS2) were made from cDNA of L. salmonis with primers listed in Table 1. The sense probe was used as a negative control. The probes were visualized by using anti-digoxigenin (DIG) alkaline phosphatase fragment antigen-binding (FAB) fragment (Roche, Basel, Switzerland) and staining 1-step ${ }^{\mathrm{TM}}$ NBT/BCIP plus suppressor solution (Sigma-Aldrich, St. Louis, MO, USA). Microscopy images were taken using an Axio Scope A1 light microscope connected to an Axiocam 105 (Zeiss, Oberkochen, Germany).

\subsection{Immunohistochemistry}

Chitin detection was performed by labeling paraffin-embedded L. salmonis with wheat germ agglutinin (WGA) lectin from Triticum vulgaris (Sigma-Aldrich, St. Louis, MO, USA), followed by antibody-linked staining. WGA binds specifically to $N$-acetyl- $\beta$ D-glucosamine oligomers (chitin) and $N$-acetyl-neuraminic acid (sialic acid). First, the paraffin-embedded slides ( $5 \mu \mathrm{m}$ thick) were heat treated at $45^{\circ} \mathrm{C}$ for $30 \mathrm{~min}$. Hydration was carried out by incubating the slides first in Histo-Clear II (National Diagnostics, Atlanta, USA) two times for $10 \mathrm{~min}$ and then in ethanol gradient $(2 \times 100 \%, 96 \%, 80 \%, 50 \%)$ for 3 min each. After the hydration steps, the slides were washed in distilled water for at least 5 min before blocking with $4 \%$ Bovine Serum Albumin (BSA) for one hour. After blocking, the slides were incubated for $45-60 \mathrm{~min}$ at $37^{\circ} \mathrm{C}$ with $200 \mu \mathrm{L}$ of WGA $(1 \mu \mathrm{g} / \mathrm{mL})$ diluted in $1 \%$ Tris Buffered Saline (TBS) buffer (Sigma-Aldrich, St. Louis, MO, USA). The negative controls were incubated in the buffer only. Thereafter, the slides were washed once in $1 \%$ TBS before $50 \mu \mathrm{L}$ of the primary antibody (anti-WGA produced in rabbit, (Sigma-Aldrich, St. Louis, MO, USA), 1:10,000) diluted in 1\% TBS-Tween (TBST) were added to each slide. The slides were incubated with the antibody for one hour at room temperature or overnight at $4{ }^{\circ} \mathrm{C}$. After incubation with the primary antibody, the slides were washed $3 \times$ in TBSTween (Sigma-Aldrich, St. Louis, MO, USA) for $10 \mathrm{~min}$, before the slides were incubated for $30 \mathrm{~min}$ in the secondary antibody diluted in TBST (goat anti-rabbit IgG, (whole molecule, Sigma-Aldrich, St. Louis, MO, USA) 1:250). After the incubation, the slides were washed $3 \times$ in TBST for $10 \mathrm{~min}$, then flushed with a processing buffer $(100 \mathrm{mM}$ Tris- $\mathrm{NaCl}, 50 \mathrm{mM}$ $\mathrm{MgCl}_{2}, \mathrm{pH}$ 9.5) and then incubated for $10 \mathrm{~min}$ in the processing buffer. After the incubation, the slides were incubated in the staining 1-step ${ }^{\mathrm{TM}} \mathrm{NBT} / \mathrm{BCIP}$ plus suppressor solution (Thermo Scientific ${ }^{\mathrm{TM}}$, Waltham, MA, USA) until the staining became visible to the naked eye ( 1 $\mathrm{min})$. The reaction was stopped by transferring the slides into distilled water. The slides were mounted using ImmunoHistoMount (Sigma-Aldrich, St. Louis, MO, USA), while some of the slides were rehydrated in ethanol solutions $(96 \%, 100 \%, 100 \%)$ for $1 \mathrm{~min}$ each and washed 2x in Histo-Clear II (National Diagnostics, Atlanta, GA, USA) for 5 min and mounted with the Histomount (Life Technologies, Carlsbad, CA, USA).

The reaction's specificity was checked by analyzing a range of controls, leaving out the WGA, the primary, or the secondary antibody in the assay. Furthermore, some slides were treated with chitinase (Trichoderma viride, Sigma-Aldrich, St. Louis, MO, USA): dsLsCHS1-injected female lice were treated for $2 \mathrm{~h}$ using $2 \mathrm{mg} / \mathrm{mL}$ of chitinases, and dsLsCHS2-injected females for $1 \mathrm{~h}(2 \mathrm{mg} / \mathrm{mL})$ or overnight $(1 \mathrm{mg} / \mathrm{mL})$. Control sections of adult $L$. salmonis were treated with $0.5 \mathrm{mg} / \mathrm{mL}$ chitinases for $1-3 \mathrm{~h}$ or overnight. The reactions were performed at $37^{\circ} \mathrm{C}$, except for overnight reactions at $4{ }^{\circ} \mathrm{C}$. All chitinase treatments were performed in $50 \mathrm{mM}$ citrate buffer $\mathrm{pH} 5.5$.

\subsection{Statistical Analysis}

Statistical analysis was performed using a Student's $t$-test or one-way analysis of variance (ANOVA), followed by Tukey's post hoc test for multiple comparisons. Ct values obtained from the RNAi experiments were used to analyze the statistical differences between the control group and the experimental group. An independent sample $t$-test 
(Student's $t$-test) $(p<0.05)$ was performed to analyze the difference in the total length of dsRNA-injected L. salmonis and of egg strings from dsRNA-injected female L. salmonis between the control and experimental groups. The differences at termination between survivors in the control and experimental groups were also calculated. One-way ANOVA and Tukey's post hoc tests were used to analyze the significant differences between the gene expression in tissues/organs studied. Microsoft Excel 2019 was used to calculate the Student's $t$-test. One-way analysis of variance was performed using Statistical Package for the Social Sciences (SPSS) 22.0 software (IBM, Armonk, NY, USA).

\section{Results}

\subsection{Localization of LsCHSs}

The tissue-specific expression of LsCHS1 and LsCHS2 transcripts was analyzed quantitatively using qPCR and qualitatively by in situ hybridization. Expression of LsCHS1 in adult female L. salmonis was found in all organs and tissue types analyzed: Integument, oocytes, ovaries, fertilized eggs, and intestine (Figure 2). LsCHS2 was also detected in all tissues and organs tested apart from the fertilized eggs. Low levels of expression of both LsCHS1 and LsCHS2 was detected in ovaries and oocytes. High individual variations of LsCHS2 levels were observed in ovaries and oocytes, likewise for LsCHS1 in oocytes. The highest expression level was found in the fertilized eggs for LsCHS1 and in the intestine for LsCHS2. In situ hybridization demonstrated LsCHS2 in muscles, intestine, ovaries, and oocytes in adult female L. salmonis (Figure 3). In situ hybridization for LsCHS1 was unsuccessful.

\subsection{WGA Signals in Female Lice}

Chitin was detected in adult female L. salmonis using a lectin WGA assay, a commonly used method to detect chitin. The staining assay showed signals in the cuticle, ovaries, oviducts, eyes, mouth tube, papilla, around the microvilli on the midgut epithelial cells, chorion around the eggs, and egg strings (Figure 4). WGA signals were strongly reduced after chitinase treatment (Figure 4) in all tissues and organs except the ovaries (Figure 4C). Additionally, overnight digestion with chitinases was tested. After the overnight incubation with chitinases, most of the louse tissues had loosened up, and morphological structures became unrecognizable when analyzed under a microscope after mounting, especially the tissue in the cephalothorax, and could not be analyzed further. The structure of oocytes in the genital segment was, however, still intact. Overnight incubation with chitinases completely reduced the WGA signals in the cuticle and inside the oocytes (Figure 4ai). WGA signals were still found on the edge of the oocytes (Figure 4ai). A range of control stainings were performed to analyze for unspecific signals (Table S1), revealing that the primary antibody produced unspecific signals in the intestine.

\subsection{RNAi-Mediated Knockdown of LsCHSs}

RNAi experiments were performed to explore the functional role of LsCHS1 and LsCHS2 enzymes in the parasitic stages of male and female lice. qPCR was used to confirm the silencing efficiency of dsRNA targeting either LsCHS1 or LsCHS2 in pre-adult II. Instar stages differ between some individual lice, causing broad gene expression variants. The analysis confirmed that LsCHS1 was significantly $(p<0.01)$ reduced by $88 \%$ in males and $85 \%$ in females (Figure 5, left panel). Similarly, the expression of LsCHS2 was significantly $(p<0.01)$ reduced by $71 \%$ in males and $86 \%$ in females (Figure 5 , right panel).

\subsection{Functional Impact of CHS Knockdown}

Four independent RNAi trials were performed in the study: Two performed in preadult II females and two in pre-adult II males. In each trial, two experiments were performed, either knocking down LsCHS1 or LsCHS2. The trials setups are explained in detail in Section 2.2.3. 


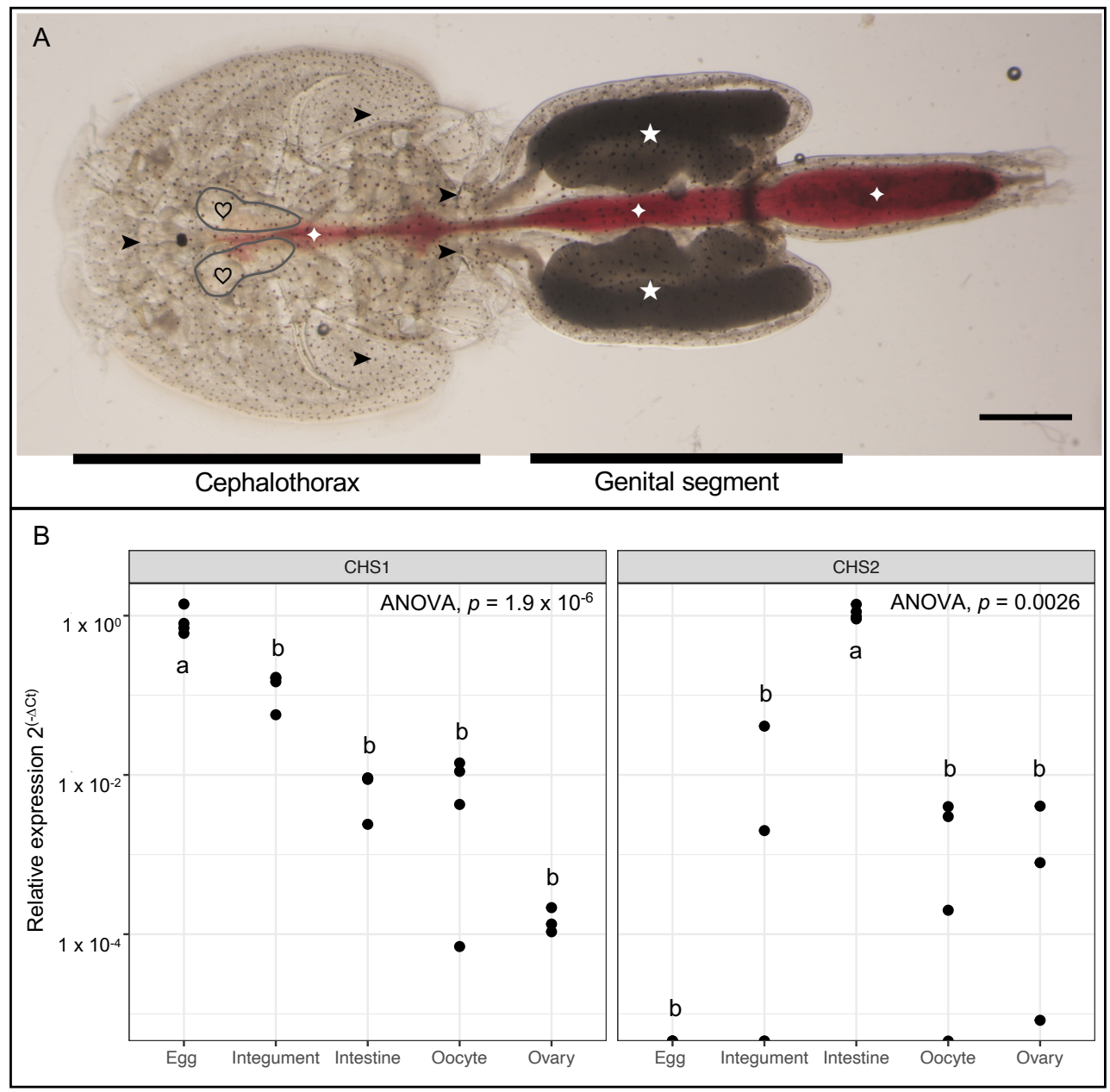

Figure 2. The transcriptional levels of LsCHS1 and LsCHS2 in tissues and organs in adult females. (A) Gross morphology of adult female L. salmonis. From the cephalothorax (ct), the ovaries (gray lines, hearts) and the integument (arrowheads) were extracted. The oocytes (stars) were extracted from the genital segment (gs). The blood-filled intestine (diamonds) extending from ct to gs was extracted. (B) The transcriptional levels of LsCHS1 and LsCHS2 were measured in dissected tissues and organs besides eggs using qPCR analysis $(n=3$ biological replicates for the ovaries, and $n=4$ for remaining tissues). The qPCR results were normalized to the reference genes (eEF1 $\alpha$, ADT3, and 18S). The relative expression levels are log-transformed, and letters indicate significant differences ( $p<0.01$, one-way ANOVA, Tukey's test). The scale bar is $1 \mathrm{~mm} .1 \times 10^{-2}$.

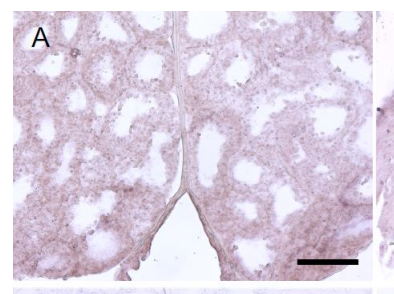

a

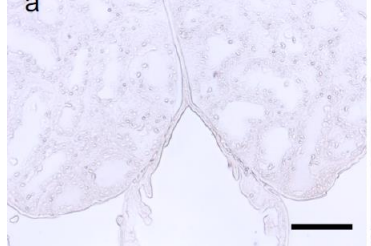

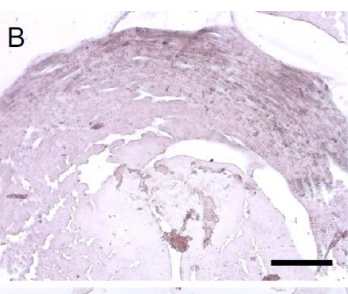

b

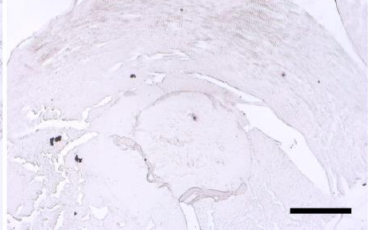

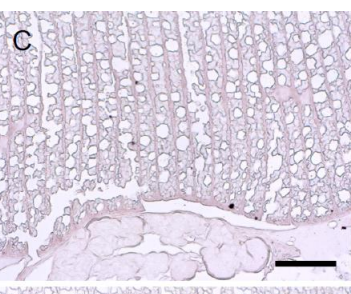

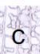

c

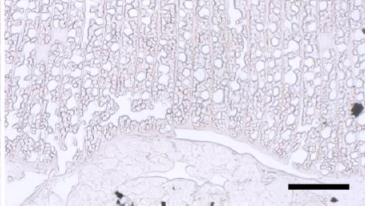

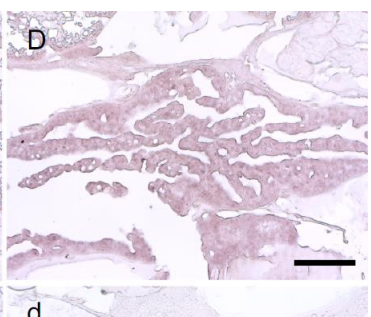

d

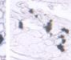

Figure 3. In situ hybridization of LsCHS2 in sections of adult females. Positive stainings were detected in ovaries (A), muscles (B), intestine (C), and oocytes (D) using LsCHS2-specific anti-sense probes. Sense probes (a-d) show no unspecific staining. The scale bars are $100 \mu \mathrm{m}$. 


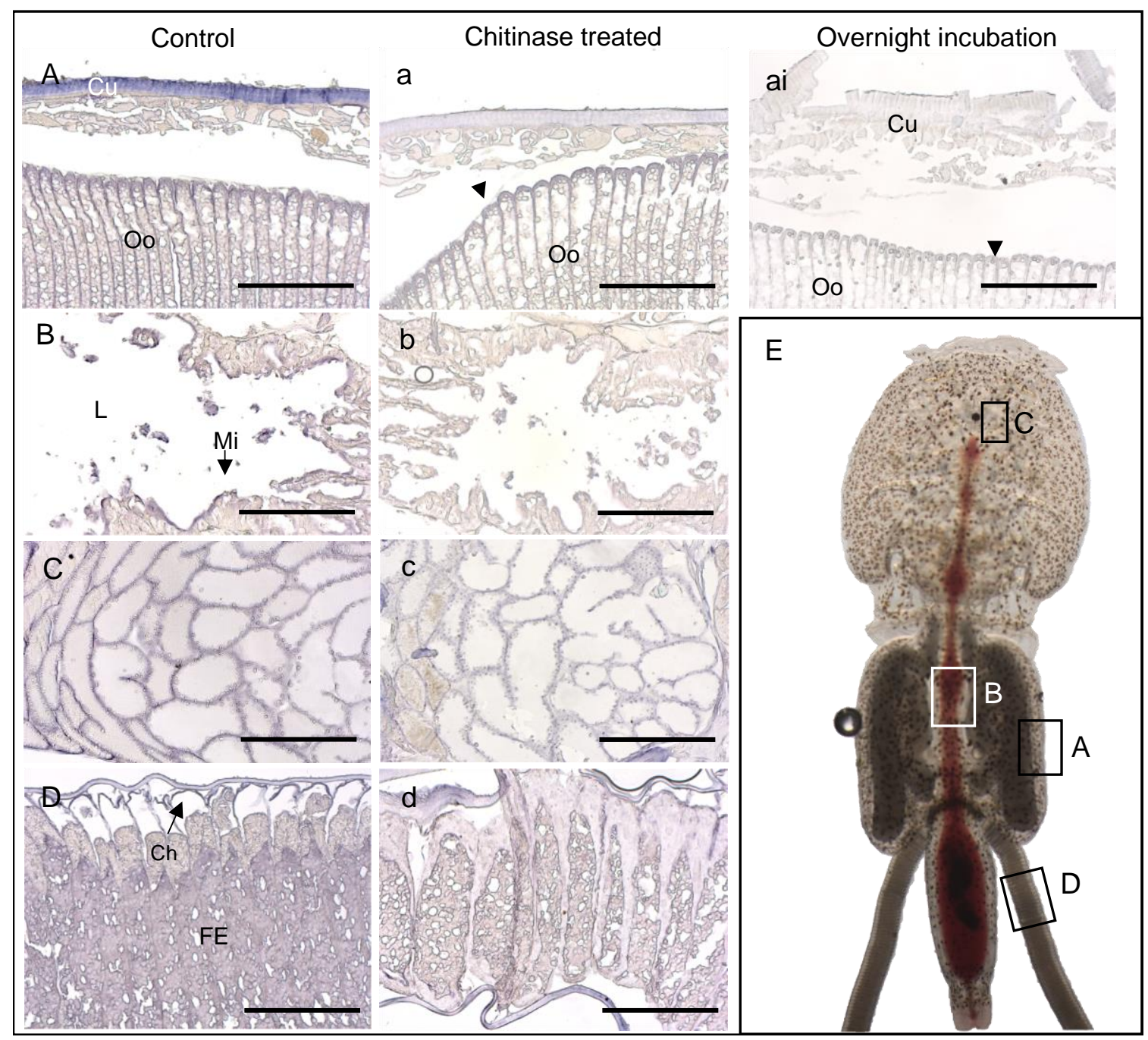

Figure 4. Wheat germ agglutinin (WGA) staining in female louse. WGA-labeled (paraffin) sections of control L. salmonis injected with dsCPY. (A) WGA stainings in oocytes of the genital segment and cuticle; (B) intestine, WGA staining around the microvilli (see arrow); (C) ovary, WGA signals around and inside the follicles; (D) egg string, WGA staining in the fertilized eggs, chorion (see arrow), and the layer (outermost) of the egg string. Corresponding parallel sections from the same louse treated with $0.5 \mathrm{mg} / \mathrm{mL}$ chitinases for $1 \mathrm{~h}(\mathbf{a}-\mathbf{c}), 3 \mathrm{~h}(\mathbf{d})$, and overnight (ai). (E) Gross morphology of adult female louse indicating where (A-D) are located. (a,ai) The arrowheads demonstrate the WGA signals on the edge of the oocytes. Cuticle $(\mathrm{Cu})$, chorion $(\mathrm{Ch})$, fertilized eggs (FE), lumen (L), microvilli (Mi), and oocytes (Oo). (A-D, a-d) The scale bars are $100 \mu \mathrm{m}$.

\subsubsection{Knockdown of LsCHSs Induced Loss of Lice from the Fish}

After dsRNA injection into the pre-adult I stage of L. salmonis, losses of some lice during an experiment are normal (personal observations) [41]; however, here a significant loss of lice was observed in some trials. In females (trials 3 and 4), loss of LsCHS1 knockdown lice from the fish began as pre-adult II females reached the adult stage. Lice retrieved from filtered water outlet from the fish tanks containing LsCHS1 knockdown lice showed morphological changes compared to controls. In trial 4, at the end of the experiment, all of the LsCHS1 knockdown lice were lost from the host. The loss of lice after LsCHS2 knockdown did not occur before development to the adult stage, where females with an aberrant appearance of the intestine and lack of intestinal host blood were observed in the water outlet. LsCHS1 knockdown in males (trials 1 and 2) triggered a loss of lice, starting 
when they reached the adult stage. Similar morphological changes were observed in males as in LsCHS1 knockdown females. For LsCHS2 knockdown, no significant loss or abnormal morphology was observed in male lice.
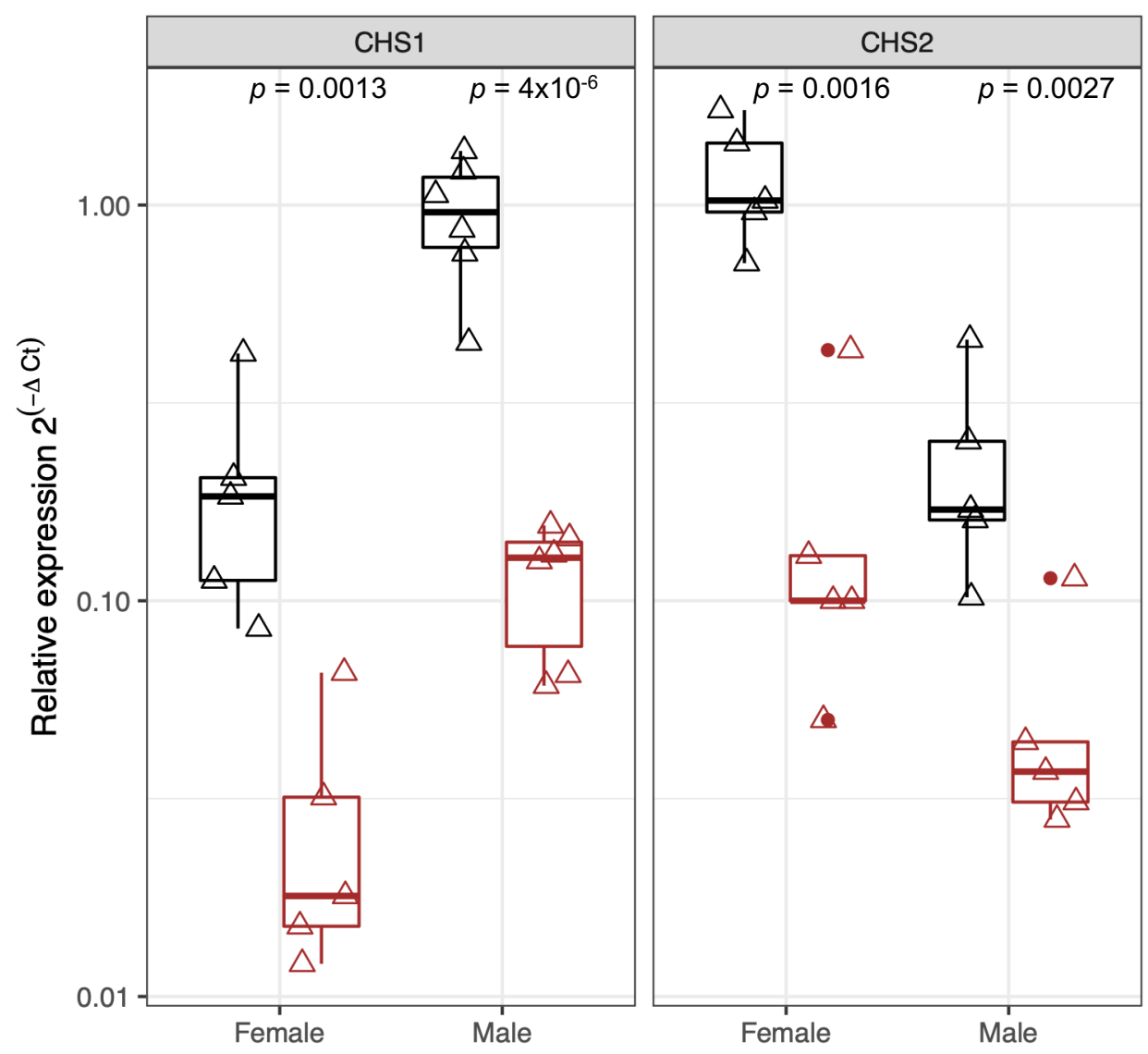

Figure 5. Relative expression of LsCHS1 and LsCHS2 in individual pre-adult II L. salmonis injected with dsLsCHS1 and dsLsCHS2 (CHS1 left and CHS2 right, brown), respectively, with comparable dsCPY controls (black). The qPCR results were normalized to the reference genes (eEF1 $\alpha$, ADT3, and 18S). One individual louse in the LsCHS2 male group shows low knockdown effects. Each triangle represents an individual sample, and outliers are marked with a circle, $(p<0.01, t$-test). The relative expression levels are log-transformed.

\subsubsection{Knockdown of LsCHS1 Affected the Cuticle and the Subcuticular Layer}

The silencing of LsCHS1 resulted in aborted molting and abnormal cuticle formation in both female and male lice. The knockdown of LsCHS2 did not have any observable effect on ecdysis and development in L. salmonis.

Development of males from the pre-adult I to the adult stage was followed to observe any effects of gene knockdown (trial 1). Two dsLsCHS1-injected abnormal males were found in the water outlet: One pre-adult II with incomplete molt to the adult stage, and one adult with an abnormally flexible cuticle. At termination, $56 \%$ of dsLsCHS1-injected males were recovered, but no adult lice, while $64 \%$ of control dsCPY-injected males were found, including $13 \%$ adults. In the second RNAi trial (trial 2), males injected with dsLsCHS1 were harvested earlier to analyze if any histological changes had occurred in pre-adult II. At termination, there was no difference in survival between control and LsCHS1-injected lice, which both had a survival of approximately $47 \%$. Histological analysis of the pre-adult II males revealed no abnormalities after dsLsCHS1 injection.

RNAi knockdown of LsCHS1 was examined in females in two separate experiments (trials 3 and 4). During trial 3, both pre-adult II and adult female lice with abnormal 
morphology were found in the water outlet. A total of $12 \mathrm{dsLSCHS1-injected} \mathrm{female} \mathrm{lice}$ were found in the water outlet seven to eight days post-injection. These lice were unable to swim and attach to a surface. A range of phenotypes ranging from mild to more severe were observed. These were for simplicity categorized into three types: (A) Phenotype 1 ( $42 \%$ of the lice): Lice with incomplete molt to the adult stage. Exuvia was partially shed and typically found in the middle of the cephalothorax (Figure 6A). (B) Phenotype 2 (33\% of the lice): Lice developed to the adult stage, but with abnormally flexible cuticle and abnormal morphology of the genital segment (Figure $6 \mathrm{~B}$ ), and (C) phenotype 3 ( $25 \%$ of the lice): Lice similar to phenotype 2 but with more aberrant body morphology (Figure 6C).

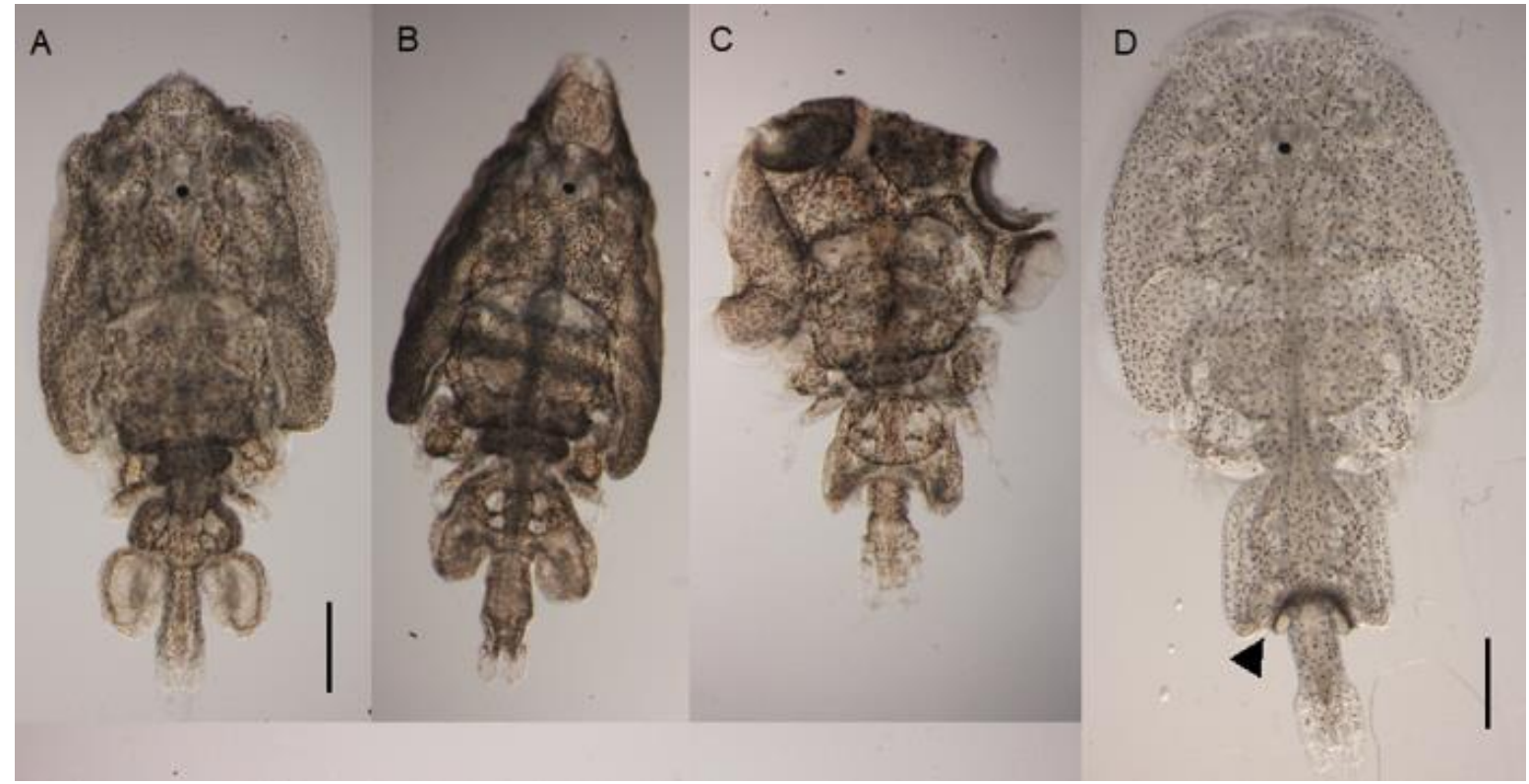

Figure 6. Phenotypes severity observed in female lice injected with dsLsCHS1. (A-C) The three phenotypes were obtained in the dsLsCHS1 groups. (A) Phenotype 1, pre-adult II arrested molt to adult. (B) Phenotype 2, adult louse with flexible cuticle and abnormal morphology. (C) Phenotype 3, similar to phenotype 2 but with more dramatic changes to the morphology. (D) An adult female louse from the control groups with spermatophore attached to the genital segments (arrow). The scale bars are $1 \mathrm{~mm}$.

At termination in trials 3 and 4, none of the lice injected with dsLsCHS1 was found on the fish. For the dsCPY-injected control lice, $40-50 \%$ in trials 3 and 4 recovered. Thirty-six percent of the female control lice were pre-adult II, and the rest were immature adults (T2-T3 as described by [13]).

Histological analysis of sections revealed that the morphology of the cuticle in females injected with dsLsCHS1 differed from control animals. Lice with phenotype 1 and 2 had two exoskeletons present in the integument. For phenotype 2, this was typically around the genital segment only, whereas in lice with phenotype 1, this could be observed both in the cephalothorax and in the genital segment. Whereas control L. salmonis had a single cuticle with two to three distinguishable layers, LsCHS1 knockdown female lice had produced a thinner cuticle with no observable layers (Figure 7Ai,ii). The epithelial cell morphology in the LsCHS1 knockdown females differed from the control lice and appeared damaged (Figure 7Ai,ii), with the cuticle detaching from the epidermis layer (Figure 7Ai). The subcuticular tissues were necrotic (Figure 7Ai,ii). The WGA staining indicated a reduced amount of chitin in the cuticle of dsLsCHS1 compared to the control dsCPY-injected lice (Figure 7Bi). Before WGA staining, the LsCHS1 and LsCPY knockdown female louse sections were digested with chitinases to analyze if the WGA signals in the cuticle of the LsCHS1 knockdown females were reduced faster than the cuticle of LsCPY knockdown 
females. The chitinase treatment only reduced the WGA signals in the cuticle of the control lice, while all WGA signals were absent in the cuticle of dsLsCHS1 lice (Figure 7Bii).

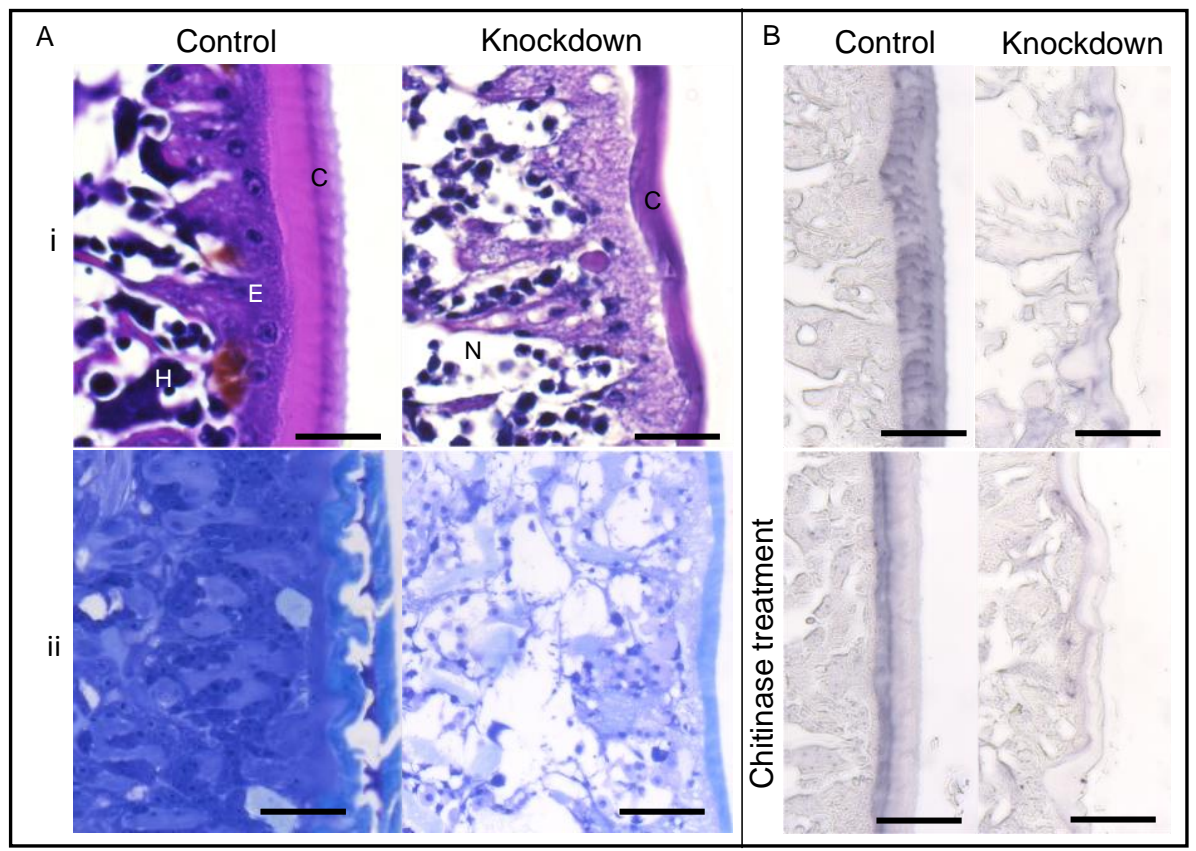

Figure 7. Morphology of the integument in dsLsCHS1-injected female lice. (A) Hematoxylin and erythrosin B (H\&E)-stained paraffin section (panel i) and toluidine-stained plastic section (panel ii) of the cuticle and subcuticular layer in dsCPY- and dsLsCHS1-injected female lice. (B) WGA labeling of chitin in CPY or LsCHS1 knockdown L. salmonis (upper) and after chitinase treatment (lower). Cuticle (C), epithelium cells (E), hemolymph $(\mathrm{H})$, and necrotic tissue $(\mathrm{N})$. The scale bars are $25 \mu \mathrm{m}$.

\subsubsection{LsCHS Knockdown Affected Blood Feeding and Growth Digestion}

Silencing of LsCHS1 or LsCHS2 induced morphological changes of the intestine and affected the feeding behavior. No abnormalities were observed in the digestion tract of males injected with dsLsCHS1 or dsLsCHS2 (trials 1 and 2).

The largest morphological alterations were observed in females injected with dsLsCHS1 with phenotype 3 (Figure S1, Figure 6). Further investigation of the effect on the digestive tract was not performed. During the dsLsCHS2-induced knockdown in trials 3 and 4, three and four adult female lice, respectively, were collected from the water outlet with abnormal intestinal appearance. When these lice were placed on a slide under a cover-glass to study morphology further, the intestine completely disintegrated (Figure S2).

At the termination of trial 3, there were no significant differences in the number of lice recovered between the control dsCPY and dsLsCHS2 groups. However, in trial 4, there was a significant difference in survival between dsLsCHS2 and control dsCPY-injected female lice, with three and 15 lice found on the fish, respectively $(p<0.05)$. Almost all the control lice had visible blood in the intestine, while the dsLsCHS2 lice had no visible or a strongly reduced amount of blood in the intestine (Figure 8A). Visual analysis of live lice showed that peristaltic movements of the gut observed in control lice were completely absent in the LsCHS2 knockdown females and the muscular contractions around the intestine (Figure 8Ai). Histological analysis revealed malformations in the midgut of dsLsCHS2-injected female lice ranging from a normal-looking intestine to large deformations (Figure 8Aii). In the dsCPY control louse sections, the muscle and microvilli were observed, while in some dsLsCHS2 knockdown females, the amount of muscle was reduced, and microvilli were disordered. WGA staining was not observed in LsCHS2 knockdown lice with large deformations in the intestine (Figure 8Aiii). The microvilli 
appeared damaged, and the epithelium cells covering the digestive tract appeared unstructured in LsCHS2 knockdown females (Figure 8B). Histopathological alternations, including hypertrophy and desquamation, were observed (Figure 8B).

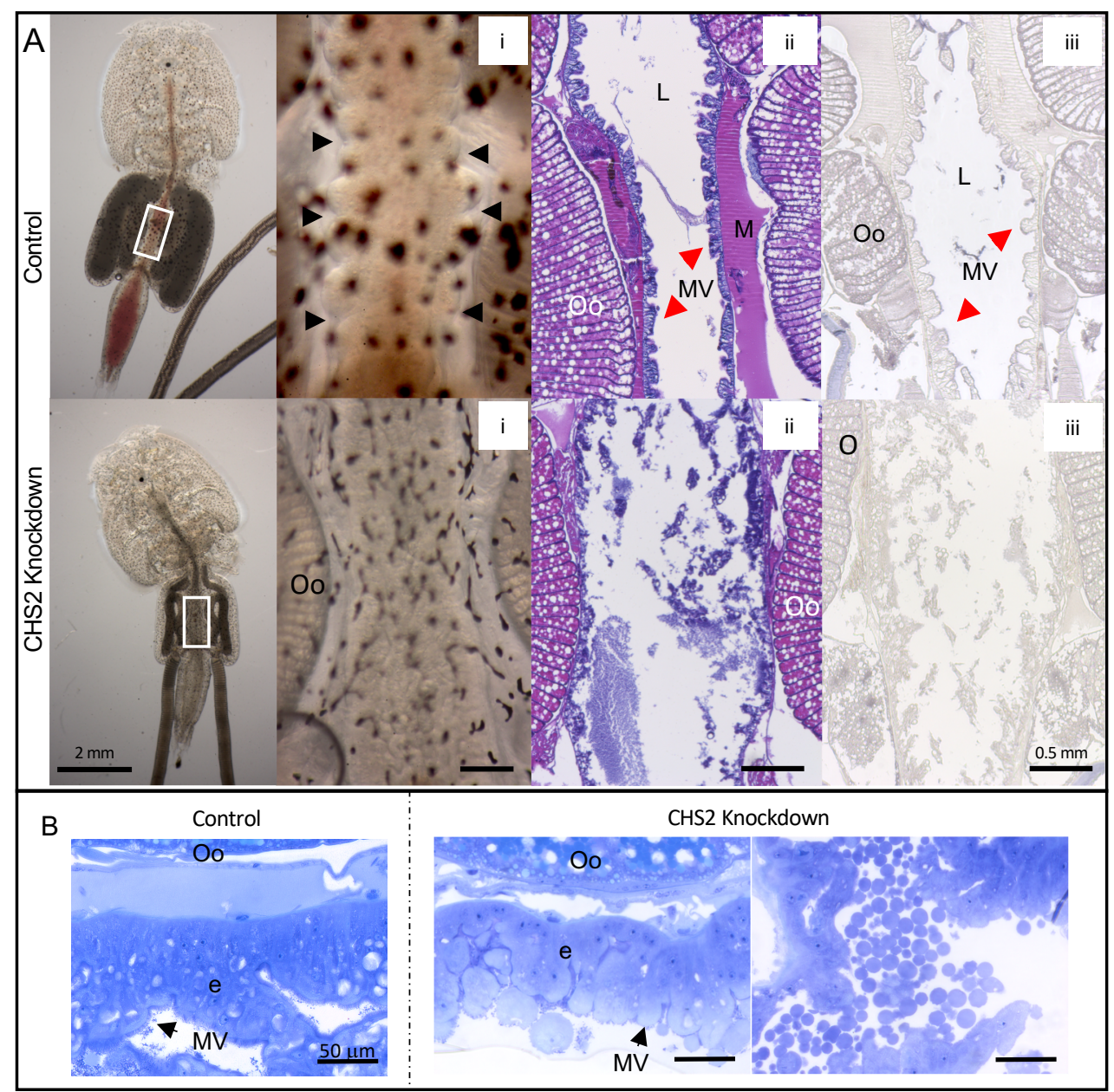

Figure 8. Morphology of the intestine comparing LsCHS2 knockdown and control Lepeophtheirus salmonis females. Representative photos of female lice injected with either dsCPY (control) or dsLsCHS2. (A) The midgut of control lice (upper) and experimental lice (below). The white squares (first photo) illustrate where the other images are taken (i-iii). The intestine of the control and experimental lice (i); arrowheads indicate the contraction in the control intestine (i). H\&E-stained paraffinembedded sections (ii), and WGA-labeled sections (iii) of the midgut. The microvilli are damaged with reduced WGA signals in the intestine of the dsLsCHS2-injected female louse compared to the intestine of the controls. (B) Histopathological analysis of toluidine-stained sections of control and experimental female lice. LsCHS2 knockdown louse epithelial cells and damaged microvilli (right image), particles were observed in the LsCHS2 knockdown louse (left image). The lumen of the intestine (L), muscle (M), and microvilli (MV). (A) The scale bars are $0.5 \mathrm{~mm}$ (i-iii). (B) The scale bars are $50 \mu \mathrm{m}$.

\section{Growth}

Both LsCHS1 and LsCHS2 knockdown females were significantly $(p<0.01)$ shorter than the control lice. The average length of LsCHS1 knockdown immature adult females ( $\sim \mathrm{T} 2)$ was $\sim 7 \mathrm{~mm}$ compared to $\sim 9.5 \mathrm{~mm}$ for the control lice (T2) (Figure S3A,B). The average lengths of LsCHS2 and CPY control knockdown adult lice were $10.5 \mathrm{~mm}$ and $12.1 \mathrm{~mm}$, respectively (Figure S3A,B).

\subsubsection{LsCHS Knockdown Affected the Reproductive Organs and the Offspring}

The silencing of LsCHS1 or LsCHS2 in females (trials 3 and 4) induced changes in the ovaries, oocytes, and eggs. Females treated with dsLsCHS1 had a malformed genital 
segment (Figure 6). Histological examination revealed that the LsCHS1 knockdown females with phenotype 1 had oocytes of normal appearance, while abnormalities were apparent in the oocytes and the ovaries of lice with phenotypes 2 and 3 (Figure 9A,B). The oocyte organization in adult LsCHS1 knockdown deviated from the control, and the follicle inside the ovaries appeared irregular and smaller. All the dsLsCHS1-injected lice fell off the fish before they reached the mature adult stage, and hence reproduction could not be monitored.

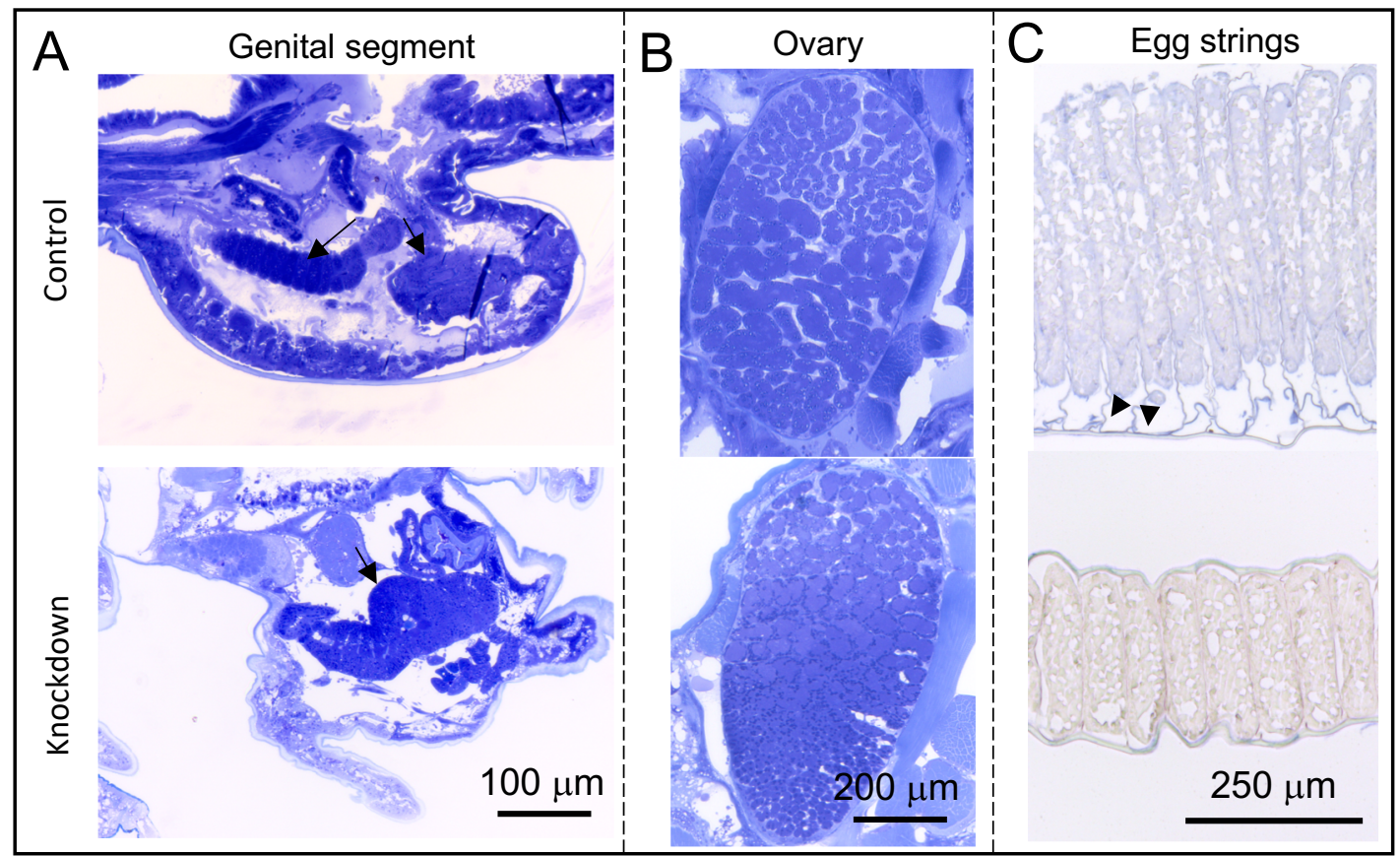

Figure 9. Effect of dsLsCHS1 and dsLsCHS2 treatment on the reproduction of female Lepeophtheirus salmonis. (A,B) Sections of CPY control (upper) and LsCHS1 knockdown (below) females. (A) Toluidine blue-stained sections of the genital segment, the arrows indicate the oocytes. (B) Toluidine blue-stained sections of the ovaries. (C) WGA-labeled (paraffin-embedded) sections of the egg strings from CPY control (upper) and LsCHS2 knockdown (below) females, the arrowheads indicate the chorion (the layer around the eggs).

The oocytes of dsLsCHS2-injected females displayed normal morphology, but the egg strings were significantly shorter (approximately 50\%) than the egg strings from the control lice (Figure S3C). The appearance of the oocytes and WGA staining signals in LsCHS2 knockdown females did not differ from the control females (Figure S4). In female control lice, strong WGA staining was detected in the chorion, as well as in the eggs and in the outermost layer of the egg strings, indicating a chitin component there (Figure 9C). In the egg strings of LsCHS2 knockdown females, no or faint WGA signals were observed (Figure 9C).

At the termination of trial 3, most females carried eggs: Six of nine lice injected with dsLsCHS2, and 11 of 12 control lice. Larvae from dsLsCHS2-treated females, however, exhibited reduced hatching success (Figure 10B), arrested molt to nauplius II (Figure 10C), or developed into copepodids with partially shed exuvia (Figure 10E) or with air bubbles inside the intestine (Figure 10F). All control larvae had normal development (Figure 10D). In trial 4, three egg strings were collected from the dsLsCHS2 females, but none hatched. Larvae from the control group developed normally. The structure of one of the egg strings produced by an LsCHS2 knockdown female from trial 4 is shown in Figure 10G. 


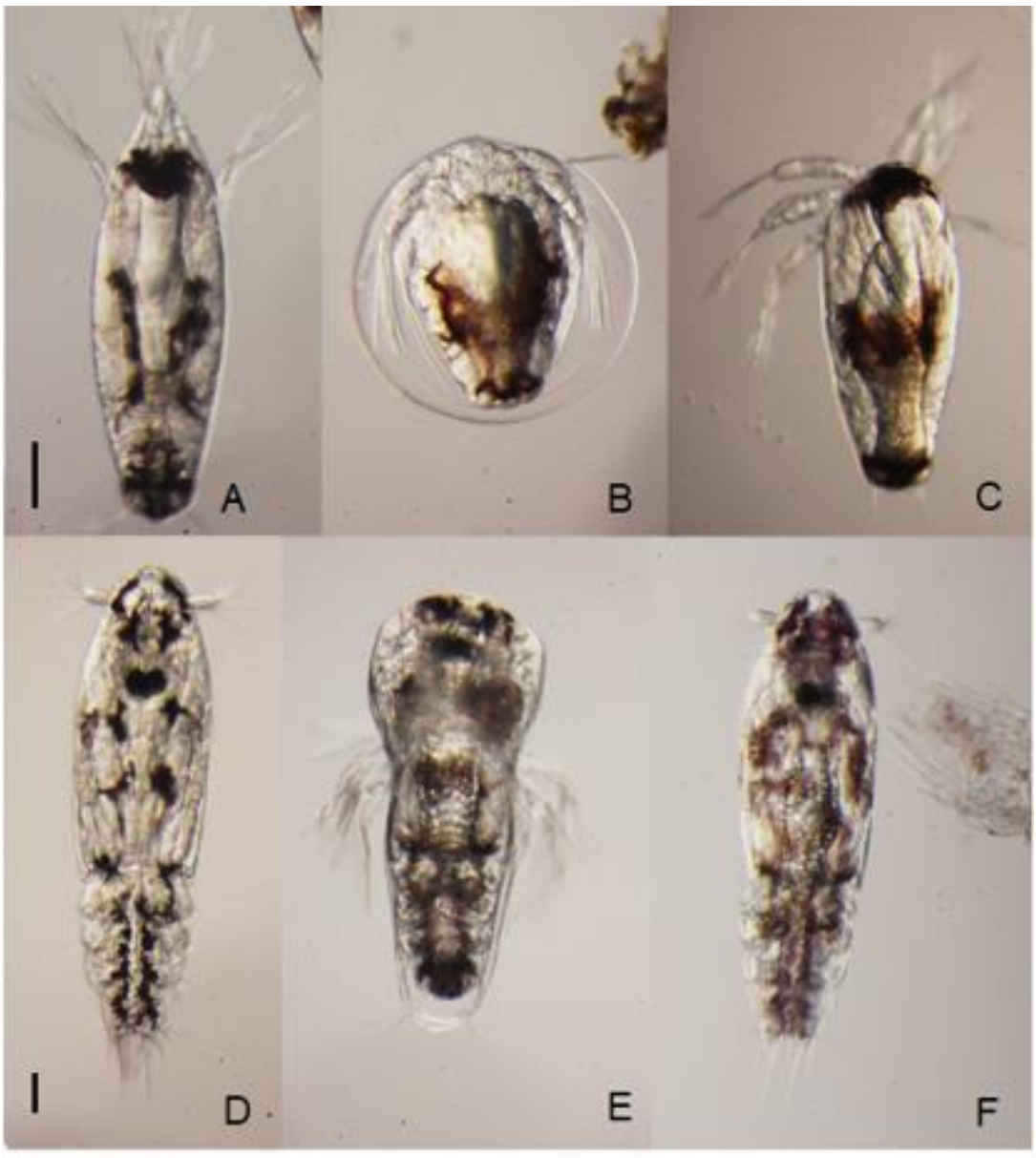

G
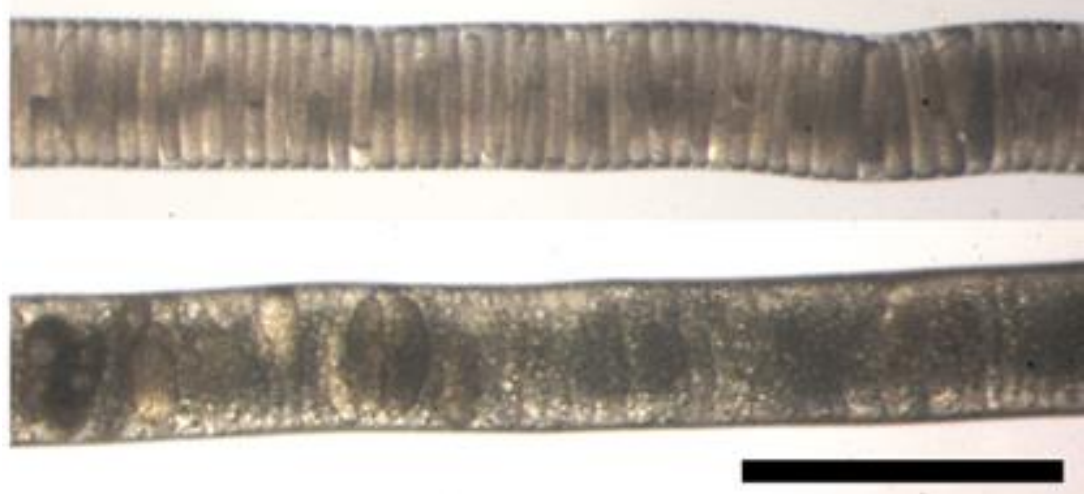

Figure 10. Larvae and eggs from dsLsCHS2-injected female Lepeophtheirus salmonis. Larvae from control females: Nauplius II and copepodid (A,D). Larvae from dsLsCHS2 females from trial 3 (B,C,E,F). Larvae with incomplete hatching (B), nauplius II arrested molt completely (C), copepodid arrested molt during ecdysis (E), and copepodid with an abnormal intestine (F). The second set of egg string pairs from adult female dsCPY (above) and dsLsCHS2 (below) lice from trial 4 (G). (A-F) The scale bars are $0.1 \mathrm{~mm}$ and $(\mathrm{G}) 1 \mathrm{~mm}$.

Reproduction in females on fish together with dsLsCHS1-injected males was not followed. Females placed on fish together with dsLsCHS2-injected males reproduced normally and had viable offspring. 


\section{Discussion}

Lepeophtheirus salmonis possesses two CHSs, LsCHS1 and LsCHS2. RNAi-mediated knockdowns of CHSs have shown that CHS1 and CHS2 are required for development, survival, egg hatching, oviposition, and oogenesis in diverse insects [29,36,37,44,45], which is similar to phenotypes obtained in insects treated with benzoylurea $[46,47]$.

\subsection{Chitin Detection by WGA and In Situ Localization of LsCHS2}

We detected chitin in the cuticle, eyes, ovaries, oviduct, oocytes, papilla, mouth tube, epithelial cells in the gut, and the fertilized egg string of $L$. salmonis. Chitin components have also been reported in these tissues and organs in pancrustaceans [48-51].

WGA staining is commonly used to analyze chitin levels. WGA staining has been documented in the integument and midgut of several arthropods [49,50,52-54], in the egg, eggshell, and ovaries of Aedes aegypti [48], and the reproductive organs in the copepods Oithona nana and Oithona similis [49]. Similar to our results in adult females, WGA staining has been detected in the cuticle, intestine, and reproductive organs of the copepods Oithona nana and Oithona similis. WGA staining was also detected in the reproductive system of Oithona males [49].

In situ hybridization of CHSs has been performed in a few insect species. Here, CHS2 was located in situ in the midgut epithelial cells, similar to what has been shown for insect CHS2 $[16,55,56]$. However, CHS2 localization in muscles or reproductive organs has not been reported in insects, like we could observe here, indicating that LsCHS2 has additional functions compared with insects.

\subsection{LsCHS1 and LsCHS2 are Also Expressed in the Reproductive Organs and Intestine}

From the first studies on CHSs in insects, it was assumed that CHS1 was specific to the integument and CHS2 to the midgut; however, later studies have shown that both CHSs are expressed in the reproductive system. Similarly to our findings, CHSs have been reported in the eggs of the mosquitoes A. gambiae [56] and Culex pipiens pallen [57] and in the ovaries and eggs of the planthopper Sogatella furcifera [58], as well as in the ovaries of the triatomine bug Rhodnius prolixus [20] and oriental armyworm Mythimna separata [58]. LsCHS1 and LsCHS2 were not highly expressed in the ovaries and oocytes but their importance for reproduction in L. salmonis possibly earlier in development cannot be excluded. The expression of LsCHS1 in fertilized eggs can indicate the importance for embryogenesis in L. salmonis. Similar to insect CHS2, the expression of LsCHS2 was not detected in fertilized eggs [59].

We could detect LsCHS1 mainly in the integument, while LsCHS2 was mainly found in the intestine of adult female L. salmonis. These results are comparable to insect CHS1 and CHS2, e.g., in the beetle Leptinotarsa decemlineata [60], the moth Manduca sexta [28], the beet armyworm Spodoptera exigua [61,62], and the mosquito Anopheles gambiae [56]. CHS1 and CHS2 expression in insects has also been reported in the intestine and integument, respectively. In the intestine of insects, CHS1 is mainly found in the foregut and hindgut, not midgut $[56,60]$, and CHS2 has been reported to be expressed at low levels in the integument of Ostrinia furnacalis [63] and M. sexta [28]. Similar to what we observed in the present study, LsCHS1 was expressed at low levels in the intestine and LsCHS2 in the integument. The result presented in this study shows that LsCHS1 and LsCHS2 are mainly expressed in the integument and intestine, respectively. Nevertheless, both can also be found in the same tissues and organs, namely, in the integument, intestine, and reproductive organs. However, concluding from our RNAi-mediated knockdown, LsCHS1 and LsCHS2 have different functions. A previously published study also supports this finding, which includes knockdown experiments of these genes in L. salmonis larvae [35].

\subsection{Silencing the Expression of LsCHS1 Disrupts Development and Growth}

In insects, it is well documented that CHS1 is important for molting and development, while CHS2 for feeding and possibly egg production. In L. salmonis, silencing the expression 
of LsCHS1 resulted in abnormal molting and the reduction of chitin in the exoskeleton, while the silencing of LsCHS2 did not affect ecdysis or exoskeleton chitin formation. The silencing of LsCHS1 did not affect the molting of pre-adult I lice, while most pre-adult II lice exhibited abnormal molting to the adult stage. It is unlikely that the two molt processes are significantly different, but the protein level of LsCHS1 may still have been sufficient in pre-adult I to accomplish molting. Similar results are reported for LsCHS1 knockdown L. salmonis larvae, where only the second molt after treatment was affected [35]. Suppressing the expression of LsCHS1 induced changes in the cuticle structure. Some of the pre-adult lice were partially trapped inside the exuviae. In contrast, others molted to malformed adults with an incomplete exoskeleton and some with remains of the old exoskeleton. RNAi-mediated knockdown of insect CHS1 showed similar phenotypes with incomplete molt, e.g., the planthopper S. furcifera [58], the fruit fly Bactrocera dorsalis [64], the beetle L. decemlineata [60], and the pea aphid Acyrthosiphon pisum [44]. The WGA assay also supports the role of LsCHS1 in the synthesis of chitin in the exoskeleton, similar to insect CHS1.

\subsection{Silencing the Expression of LsCHS1 or LsCHS2 Interferes with the Digestive System}

RNAi knockdown of both LsCHS1 and LsCHS2 in female lice induced changes in the intestine of the experimental lice. The LsCHS1 knockdown adult females exhibited abnormal morphology of the intestine. In insects, CHS1 synthesizes chitin into the hindand foregut. If $\mathrm{LsCHS1}$ also has a similar role, this could explain the large morphological changes observed in the intestine of adult lice $[56,60]$. The silencing of LsCHS2 interfered with blood feeding, and the epithelial cells covering the intestine in adult female L. salmonis were damaged. Interestingly, no such effect was found in males, which could indicate that females are more dependent on a high expression of LsCHS2, possibly due to a higher digestive requirement for energy consumption required in the production of eggs. In some mosquitoes, blood feeding is required for egg production, and male mosquitoes do not feed on blood [65]. Yet, it is presently unknown whether blood feeding is necessary for reproduction in females. Blood can be observed in male L. salmonis, but it is currently unknown whether they are obligate blood feeders. LsCHS2 is highly expressed in pre-adult I and adult females; however, in males, the expression is several folds lower (Figure 5), which could explain why only the females had an abnormal phenotype. In trial 3, the intestine in the females was less damaged than the intestine in females in trial 4, suggesting that the damage occurs with time. The females in trial 4 were approximately two weeks older than females in trial 3.

Silencing the expression of CHS2 in insects affects the synthesis of the peritrophic matrix and damages the gut epithelium; the insects stop feeding and eventually die [29,37]. Both effects are in accordance with the putative functional similarity between L. salmonis and insects. However, L. salmonis do not seem to have a peritrophic matrix; nonetheless, they express intestine-specific $C H S[18,66]$. Insects that lack the peritrophic matrix are reported to have only one copy of CHS [20,44,67]. Many of these insects belong to the order Hemiptera and have instead a perimicrovillar membrane, an extracellular layer covering the intestinal microvilli. Unlike the peritrophic matrix, the perimicrovillar membrane increases the absorption capacity of nutrients from diluted diets [19]. As demonstrated here in L. salmonis, WGA staining in the intestinal microvilli may not be conclusive, as our results show unspecific staining in the intestine. However, after chitinase treatment, the WGA signals were reduced in the lice intestine, and the signals were mostly absent in the intestine of the dsLsCHS2 knockdown females. Taken together, these results support the role of LsCHS2 in synthesizing chitin in the midgut. In the triatomine bug R. prolixus, which lacks the peritrophic matrix, chitin is present around the midgut epithelium [50]. Based on the expression of LsCHS2 and our LsCHS2 knockdown results, it is possible that L. salmonis has a layer around the microvilli with similar protection and function as the peritrophic matrix or perimicrovillar membrane. Still, more investigation is needed before this can be shown conclusively. 
The intestine's muscular contractions were absent in LsCHS2 knockdown females, and our histological investigation showed that the muscles around the intestine appeared smaller than in control animals. However, further investigation is also needed here before clear conclusions can be drawn.

\subsection{LsCHS1 and LsCHS2 Are Important for Reproduction}

Silencing CHS expression in insects by RNAi induces changes in reproductive organs and functions such as oogenesis, oviposition, egg morphology, and hatching [20,21,36,45]. In L. salmonis, silencing the expression of either of the two CHSs affected the reproductive system but in different ways. Knocking down LsCHS1 caused structural alterations in the ovaries and oocytes, while LsCHS2 knockdown interfered with the hatching of offspring and changed the morphology of extruded eggs. Reproductive effects could not be demonstrated in LsCHS1 knockdown females, as they never reached the mature egg-producing female stage. However, the malformation in the reproductive organs indicates that these lice could not produce viable offspring. Insect CHS1 is shown to be required for embryonic development $[45,68]$. It could be speculated that $L s C H S 1$ is important for the embryonic cuticle formation as the expression of LsCHS1 is high in non-treated maturing eggs.

Silencing the expression of LsCHS2 in females showed that the majority of the larvae in the first pair of egg strings hatched (trial 3), while the larvae from the second pair of egg strings (trial 4) did not hatch. The difference in the duration of each trial, or differences in the level of knockdown, between the females could explain the differences in reproduction success. In insects, CHS2 knockdown in the beetle T. castaneum and the boll weevil Anthonomus grandis also reduced reproduction [36,37], which was caused by starvation of the mother due to a dysfunctional peritrophic matrix. The females in trial 3 had most likely enough energy to produce some offspring. The few females that survived in trial 4 were apparently not eating, and normal egg production was inhibited. A reduction of chitin in the chorion in the egg strings of LsCHS2 knockdown lice could also explain the unsuccessful hatching. Similar results are reported for $d s C H S A$-treated $T$. castaneum, where the amount of chitin was dramatically reduced in the eggs, and hatching did not take place [36]. In $R$. prolixus, the eggs produced by $d s C H S$-treated females had different morphology, and a reduction of chitin content was found in the previtellogenic and vitellogenic oocytes [20]. We could see a reduction of chitin in the ovaries in LsCHS1 knockdown females, but not in LsCHS2 knockdown females. The oocytes in the dsLsCHS2 knockdown and the control lice seem to have a similar amount of chitin.

The offspring from LsCHS2 knockdown lice may have undergone molting arrest during larval development due to a lack of nutrients caused by impaired feeding in the mother. Blood is a nutrient-rich food supply that may be optimal for egg production and development of the offspring. Lacking essential components during the development of larvae could influence developmental success. In conclusion, the roles of chitin synthases in parasitic copepod L. salmonis resemble the described roles in insects. The two CHSs appear to play diverse roles, with LsCHS1 mainly being involved in exoskeleton construction and LsCHS2 in intestinal function. Limited knowledge on CHSs is available from copepods, and future studies should investigate the role of these enzymes in molting, reproduction, and intestine.

Supplementary Materials: Supplementary materials can be found at https://www.mdpi.com/2075 $-1729 / 11 / 1 / 47 /$ s1. Table S1: Overview of the results from the WGA assays. Each line represents one assay. Plus (+) indicates the reagents used in a single analysis, and minus (-) negative controls. In the signal column, plus indicates staining, red reduced staining, and minus no staining, and antibody (Ab), Figure S1: Effects on ovaries in LsCHS1 knockdown females. (A) H\&E-stained and (B) WGAlabeled sections of control and LsCHS1 knockdown females, Figure S2: LsCHS2 knockdown female with completely disintegrated intestine: (A) Overview photo of the louse carrying eggs; (B) photo taken of the louse without coverslip; and (C) with cover slip. (A) Scale bar $1 \mathrm{~mm}$ (6.25x magnification), and (B,C) 12.5x magnification, Figure S3: The total length: (A) LsCHS1 knockdown females; (B) LsCHS2 knockdown females; and (C) egg strings from LsCHS2 knockdown females compared with 
comparable controls, Figure S4: Effects on genital segment in LsCHS2 knockdown females; (A) H\&E-stained sections; (B) toluidine blue-stained sections; and (C) WGA-labeled sections of control and LsCHS2 knockdown female lice.

Author Contributions: Conceptualization, H.M.H. and S.D; methodology, H.M.H. and S.D.; validation, H.M.H.; formal analysis, H.M.H.; investigation, H.M.H.; writing-original draft preparation, H.M.H.; writing-review and editing, H.M.H., R.M., F.N., and S.D.; visualization, H.M.H.; supervision, S.D.; project administration, F.N., R.M., and S.D.; funding acquisition, F.N., R.M., and S.D. All authors have read and agreed to the published version of the manuscript.

Funding: This research was fully funded by the Research Council of Norway, SFI-Sea Lice Research Centre, grant number 203513/O30 to H.M.H., R.M., F.N., and S.D. The funders had no role in the design of the study; in the collection, analyses, or interpretation of data; in the writing of the manuscript, or in the decision to publish the results.

Institutional Review Board Statement: The study was conducted according to the guidelines of the Norwegian legislation and the experiments were approved by the Norwegian Animal Research Authority (permits code ID8589).

Informed Consent Statement: Not applicable.

Data Availability Statement: Data is contained within the article or supplementary material.

Acknowledgments: We want to thank Per Gunnar Espeland for the help in the sea lice facility; Pavinee for helping with the plastic sections; and Heidi Kongshaug for injecting the pre-adult I salmon lice for the RNAi experiments and the RNA extraction of the ovaries.

Conflicts of Interest: The authors declare no conflict of interest. The funders had no role in the design of the study; in the collection, analyses, or interpretation of data; in the writing of the manuscript, or in the decision to publish the results.

\section{References}

1. Boxaspen, K. A review of the biology and genetics of sea lice. ICES J. Mar. Sci. 2006, 63, 1304-1316. [CrossRef]

2. Pike, A.; Wadsworth, S. Sealice on Salmonids: Their Biology and Control. Adv. Parasitol. 1999, 44, 234-337. [CrossRef]

3. Mackinnon, B.M. Host factors important in sea lice infections. ICES J. Mar. Sci. 1998, 55, 188-192. [CrossRef]

4. Costello, M.J. Ecology of sea lice parasitic on farmed and wild fish. Trends Parasitol. 2006, 22, 475-483. [CrossRef] [PubMed]

5. Barker, S.E.; Bricknell, I.R.; Covello, J.; Purcell, S.; Fast, M.D.; Wolters, W.; Bouchard, D.A. Sea lice, Lepeophtheirus salmonis (Krøyer 1837), infected Atlantic salmon (Salmo salar L.) are more susceptible to infectious salmon anemia virus. PLoS ONE 2019, 14, e0209178. [CrossRef]

6. Barker, D.E.; Braden, L.M.; Coombs, M.P.; Boyce, B. Preliminary studies on the isolation of bacteria from sea lice, Lepeophtheirus salmonis, infecting farmed salmon in British Columbia, Canada. Parasitol. Res. 2009, 105, 1173-1177. [CrossRef]

7. Overton, K.; Dempster, T.; Oppedal, F.; Kristiansen, T.S.; Gismervik, K.; Stien, L.H. Salmon lice treatments and salmon mortality in Norwegian aquaculture: A review. Rev. Aquac. 2018, 11, 1-20. [CrossRef]

8. Aaen, S.M.; Helgesen, K.O.; Bakke, M.J.; Kaur, K.; Horsberg, T.E. Drug resistance in sea lice: A threat to salmonid aquaculture. Trends Parasitol. 2015, 31, 72-81. [CrossRef]

9. Torrissen, O.; Jones, S.; Asche, F.; Guttormsen, A.; Skilbrei, O.T.; Nilsen, F.; Horsberg, T.E.; Jackson, D. Salmon lice-impact on wild salmonids and salmon aquaculture. J. Fish Dis. 2013, 36, 171-194. [CrossRef]

10. Fjørtoft, H.B.; Nilsen, F.; Besnier, F.; Stene, A.; Bjørn, P.A.; Tveten, A.; Aspehaug, V.T.; Finstad, B.; Glover, K.A. Salmon lice sampled from wild Atlantic salmon and sea trout throughout Norway display high frequencies of the genotype associated with pyrethroid resistance. Aquac. Environ. Interact. 2019, 11, 459-468. [CrossRef]

11. Bakke, T.A.; Harris, P.D. Diseases and parasites in wild Atlantic salmon (Salmo salar) populations. Can. J. Fish. Aquat. Sci. 1998, 55, 247-266. [CrossRef]

12. Hamre, L.A.; Eichner, C.; Caipang, C.M.A.; Dalvin, S.T.; Bron, J.E.; Nilsen, F.; Boxshall, G.; Skern-Mauritzen, R. The Salmon Louse Lepeophtheirus salmonis (Copepoda: Caligidae) Life Cycle Has Only Two Chalimus Stages. PLoS ONE 2013, 8, e73539. [CrossRef]

13. Eichner, C.; Frost, P.; Dysvik, B.; Jonassen, I.; Kristiansen, B.; Nilsen, F. Salmon louse (Lepeophtheirus salmonis) transcriptomes during post molting maturation and egg production, revealed using EST-sequencing and microarray analysis. BMC Genom. 2008, 9, 126. [CrossRef] [PubMed]

14. Ritchie, G.; Mordue, A.; Pike, A.; Rae, G. Morphology and Ultrastructure of the Reproductive System of Lepeophtheirus salmonis (Krøyer, 1937) (Copepoda:Caligidae). J. Crustac. Biol. 1996, 16, 330-346. [CrossRef]

15. Eisemann, C.H.; Binnington, K.C. The peritrophic membrane: Its formation, structure, chemical composition and permeability in relation to vaccination against ectoparasitic arthropods. Int. J. Parasitol. 1994, 24, 15-26. [CrossRef] 
16. Ibrahim, G.H.; Smartt, C.T.; Kiley, L.M.; Christensen, B.M. Cloning and characterization of a chitin synthase cDNA from the mosquito Aedes aegypti. Insect Biochem. Mol. Biol. 2000, 30, 1213-1222. [CrossRef]

17. Kelkenberg, M.; Odman-Naresh, J.; Muthukrishnan, S.; Merzendorfer, H. Chitin is a necessary component to maintain the barrier function of the peritrophic matrix in the insect midgut. Insect Biochem. Mol. Biol. 2015, 56, 21-28. [CrossRef]

18. Nylund, A.; Økland, S.; Bjørknes, B. Anatomy and Ultrastructure of the Alimentary Canal in Lepeophtheirus salmonis (Copepoda: Siphonostomatoida). J. Crustac. Biol. 1992, 3, 423-437. [CrossRef]

19. Gutiérrez-Cabrera, A.E.; Córdoba-Aguilar, A.; Zenteno, E.; Lowenberger, C.; Espinoza, B. Origin, evolution and function of the hemipteran perimicrovillar membrane with emphasis on Reduviidae that transmit Chagas disease. Bull. Entomol. Res. 2016, 106, 279-291. [CrossRef]

20. Mansur, J.F.; Alvarenga, E.S.L.; Figueira-mansur, J.; Franco, T.A.; Ramos, I.B.; Masuda, H.; Melo, A.C.A.; Moreira, M.F. Effects of chitin synthase double-stranded RNA on molting and oogenesis in the Chagas disease vector Rhodnius prolixus. Insect Biochem. Mol. Biol. 2014, 51, 110-121. [CrossRef]

21. Souza-Ferreira, P.S.; Mansur, J.F.; Berni, M.; Moreira, M.F.; Dos Santos, R.E.; Araújo, H.M.M.; De Souza, W.; Ramos, I.B.; Masuda, $\mathrm{H}$. Chitin deposition on the embryonic cuticle of Rhodnius prolixus: The reduction of CHS transcripts by CHS-dsRNA injection in females affects chitin deposition and eclosion of the first instar nymph. Insect Biochem. Mol. Biol. 2014, 51, 101-109. [CrossRef] [PubMed]

22. Urbina, M.A.; Cumillaf, J.P.; Paschke, K.; Gebauer, P. Effects of pharmaceuticals used to treat salmon lice on non-target species: Evidence from a systematic review. Sci. Total Environ. 2019, 649, 1124-1136. [CrossRef] [PubMed]

23. Philips, M.; Tang, W.J.; Robinson, M.; Daza, D.O.; Hassan, K.; Leppert, V.; Hirst, L.S.; Amemiya, C.T. Evidence of chitin in the ampullae of Lorenzini of chondrichthyan fishes. Curr. Biol. 2020, 30, R1254-R1255. [CrossRef] [PubMed]

24. Tang, W.J.; Fernandez, J.G.; Sohn, J.J.; Amemiya, C.T. Chitin is endogenously produced in vertebrates. Curr. Biol. 2015, 25, 879-900. [CrossRef] [PubMed]

25. Douris, V.; Steinbach, D.; Panteleri, R.; Livadaras, I.; Pickett, J.A.; Van Leeuwen, T.; Nauen, R.; Vontas, J. Resistance mutation conserved between insects and mites unravels the benzoylurea insecticide mode of action on chitin biosynthesis. Proc. Natl. Acad. Sci. USA 2016, 113, 14692-14697. [CrossRef] [PubMed]

26. Grigoraki, L.; Puggioli, A.; Mavridis, K.; Douris, V.; Montanari, M.; Bellini, R.; Vontas, J. Striking diflubenzuron resistance in Culex pipiens, the prime vector of West Nile Virus. Sci. Rep. 2017, 7, 11699. [CrossRef] [PubMed]

27. Porretta, D.; Fotakis, E.A.; Mastrantonio, V.; Chaskopoulou, A.; Michaelakis, A.; Kioulos, I.; Weill, M.; Urbanelli, S.; Vontas, J.; Bellini, R. Focal distribution of diflubenzuron resistance mutations in Culex pipiens mosquitoes from Northern Italy. Acta Trop. 2019, 193, 106-112. [CrossRef]

28. Hogenkamp, D.G.; Arakane, Y.; Zimoch, L.; Merzendorfer, H.; Kramer, K.J.; Beeman, R.W.; Kanost, M.R.; Specht, C.A.; Muthukrishnan, S. Chitin synthase genes in Manduca sexta: Characterization of a gut-specific transcript and differential tissue expression of alternately spliced mRNAs during development. Insect Biochem. Mol. Biol. 2005, 35, 529-540. [CrossRef]

29. Arakane, Y.; Muthukrishnan, S.; Kramer, K.J.; Specht, C.A.; Tomoyasu, Y.; Lorenzen, M.D.; Kanost, M.; Beeman, R.W. The Tribolium chitin synthase genes TcCHS1 and TcCHS2 are specialized for synthesis of epidermal cuticle and midgut peritrophic matrix. Insect Mol. Biol. 2005, 14, 453-463. [CrossRef]

30. Al-Mokhlef, A.A.; Mariy, F.M.; Emam, A.K.; Ali, G.M. Effect of teflubenzuron on ultrastructure and components of the integument in Schistocerca gregaria (Forskal) 5th instar nymphs. Ann. Agric. Sci. 2012, 57, 1-6. [CrossRef]

31. Silva, C.P.; Silva, J.R.; Vasconcelos, F.F.; Petretski, M.D.A.; DaMatta, R.A.; Ribeiro, A.F.; Terra, W.R. Occurrence of midgut perimicrovillar membranes in paraneopteran insect orders with comments on their function and evolutionary significance. Arthropod Struct. Dev. 2004, 33, 139-148. [CrossRef] [PubMed]

32. Uddowla, H.; Kim, A.R.; Park, W.; Kim, H. cDNAs Encoding Chitin Synthase from Shrimp (Pandalopsis Japonica): Molecular Characterization and Expression Analysis. Aquac. Res. Dev. 2015, 6, 298. [CrossRef]

33. Hwang, D.S.; Lee, M.C.; Kyung, D.H.; Kim, H.S.; Han, J.; Kim, I.C.; Puthumana, J.; Lee, J.S. WAFs lead molting retardation of naupliar stages with down-regulated expression profiles of chitin metabolic pathway and related genes in the copepod Tigriopus japonicus. Comp. Biochem. Physiol. Part C Toxicol. Pharmacol. 2017, 193, 9-17. [CrossRef] [PubMed]

34. Harðardóttir, H.M.; Male, R.; Nilsen, F.; Eichner, C.; Dondrup, M.; Dalvin, S. Chitin synthesis and degradation in Lepeophtheirus salmonis: Molecular characterization and gene expression profile during synthesis of a new exoskeleton. Comp. Biochem. Physiol. Part A 2019, 227, 123-133. [CrossRef] [PubMed]

35. Braden, L.; Michaud, D.; Igboeli, O.O.; Dondrup, M.; Hamre, L.; Dalvin, S.; Purcell, S.L.; Kongshaug, H.; Eichner, C.; Nilsen, F.; et al. Identification of critical enzymes in the salmon louse chitin synthesis pathway as revealed by RNA interference-mediated abrogation of infectivity. Int. J. Parasitol. 2020, 50, 873-889. [CrossRef] [PubMed]

36. Arakane, Y.; Specht, C.a.; Kramer, K.J.; Muthukrishnan, S.; Beeman, R.W. Chitin synthases are required for survival, fecundity and egg hatch in the red flour beetle, Tribolium castaneum. Insect Biochem. Mol. Biol. 2008, 38, 959-962. [CrossRef]

37. Macedo, L.L.P.; de Antonino Souza Junior, J.D.; Coelho, R.R.; Fonseca, F.C.A.; Firmino, A.A.P.; Silva, M.C.M.; Fragoso, R.R.; Albuquerque, E.V.S.; Silva, M.S.; de Almeida Engler, J.; et al. Knocking down chitin synthase 2 by RNAi is lethal to the cotton boll weevil. Biotechnol. Res. Innov. 2017, 1, 72-86. [CrossRef]

38. Hamre, L.A.; Glover, K.A.; Nilsen, F. Establishment and characterisation of salmon louse (Lepeophtheirus salmonis (Krøyer 1837)) laboratory strains. Parasitol. Int. 2009, 58, 451-460. [CrossRef] 
39. Dalvin, S.; Frost, P.; Biering, E.; Hamre, L.A.; Eichner, C.; Krossøy, B.; Nilsen, F. Functional characterisation of the maternal yolk-associated protein (LsYAP) utilising systemic RNA interference in the salmon louse (Lepeophtheirus salmonis) (Crustacea: Copepoda). Int. J. Parasitol. 2009, 39, 1407-1415. [CrossRef]

40. Frost, P.; Nilsen, F. Validation of reference genes for transcription profiling in the salmon louse, Lepeophtheirus salmonis, by quantitative real-time PCR. Vet. Parasitol. 2003, 118, 169-174. [CrossRef]

41. Øvergård, A.C.; Eichner, C.; Nilsen, F.; Dalvin, S. Molecular characterization and functional analysis of a salmon louse (Lepeophtheirus salmonis, Krøyer 1838) heme peroxidase with a potential role in extracellular matrixes. Comp. Biochem. Physiol. Part A Mol. Integr. Physiol. 2017, 206, 1-10. [CrossRef] [PubMed]

42. Livak, K.J.; Schmittgen, T.D. Analysis of relative gene expression data using real-time quantitative PCR and. Methods 2001, 25, 402-408. [CrossRef] [PubMed]

43. Dalvin, S.; Nilsen, F.; Skern-Mauritzen, R. Localization and transcription patterns of LsVasa, a molecular marker of germ cells in Lepeophtheirus salmonis (Krøyer). J. Nat. Hist. 2013, 47, 889-900. [CrossRef]

44. Ye, C.; Jiang, Y.D.; An, X.; Yang, L.; Shang, F.; Niu, J.; Wang, J.J. Effects of RNAi-based silencing of chitin synthase gene on moulting and fecundity in pea aphids (Acyrthosiphon pisum). Sci. Rep. 2019, 9, 3694. [CrossRef] [PubMed]

45. Zhai, Y.; Fan, X.; Yin, Z.; Yue, X.; Men, X.; Zheng, L.; Zhang, W. Identification and Functional Analysis of Chitin Synthase A in Oriental Armyworm, Mythimna separata. Proteomics 2017, 17, 1700165. [CrossRef]

46. Wilson, T.G.; Cryan, J.R. Lufenuron, a chitin-synthesis inhibitor, interrupts development of Drosophila melanogaster. J. Exp. Zool. 1997, 278, 37-44. [CrossRef]

47. Dean, S.R.; Meola, R.W.; Meola, S.M.; Sittertz-Bhatkar, H.; Schenker, R. Mode of action of lufenuron in adult Ctenocephalides felis (Siphonaptera: Pulicidae). J. Med. Entomol. 1999, 36, 486-492. [CrossRef]

48. Moreira, M.F.; dos Santos, A.S.; Marotta, H.R.; Mansur, J.F.; Ramos, I.B.; Machado, E.A.; Souza, G.H.M.F.; Eberlin, M.N.; Kaiser, C.R.; Kramer, K.J.; et al. A chitin-like component in Aedes aegypti eggshells, eggs and ovaries. Insect Biochem. Mol. Biol. 2007, 37, 1249-1261. [CrossRef]

49. Sugier, K.; Vacherie, B.; Cornils, A.; Wincker, P.; Jamet, J.L.; Madoui, M.A. Chitin distribution in the Oithona digestive and reproductive systems revealed by fluorescence microscopy. Peer] 2018, 2018, e4685. [CrossRef]

50. Alvarenga, E.S.L.; Mansur, J.F.; Justi, S.A.; Figueira-Mansur, J.; Dos Santos, V.M.; Lopez, S.G.; Masuda, H.; Lara, F.A.; Melo, A.C.A.; Moreira, M.F. Chitin is a component of the Rhodnius prolixus midgut. Insect Biochem. Mol. Biol. 2016, 69, 61-70. [CrossRef]

51. Alagboso, F.I.; Reisecker, C.; Hild, S.; Ziegler, A. Ultrastructure and mineral composition of the cornea cuticle in the compound eyes of a supralittoral and a marine isopod. J. Struct. Biol. 2014, 187, 158-173. [CrossRef] [PubMed]

52. Wang, L.; Li, F.; Wang, B.; Xiang, J. Structure and partial protein profiles of the peritrophic membrane (PM) from the gut of the shrimp Litopenaeus vannamei. Fish Shellfish Immunol. 2012, 33, 1285-1291. [CrossRef]

53. Štrus, J.; Tušek-Žnidarič, M.; Repnik, U.; Blejec, A.; Summers, A. Microscopy of crustacean cuticle: Formation of a flexible extracellular matrix in moulting sea slaters Ligia pallasii. J. Mar. Biol. Assoc. UK 2019, 99, 857-865. [CrossRef]

54. Aldred, N.; Chan, V.B.S.; Emami, K.; Okano, K.; Clare, A.S.; Mount, A.S. Chitin is a functional component of the larval adhesive of barnacles. Commun. Biol. 2020, 3, 31. [CrossRef] [PubMed]

55. Zimoch, L.; Merzendorfer, H. Immunolocalization of chitin synthase in the tobacco hornworm. Cell Tissue Res. 2002, 308, $287-297$. [CrossRef]

56. Zhang, X.; Zhang, J.; Park, Y.; Zhu, K.Y. Identification and characterization of two chitin synthase genes in African malaria mosquito, Anopheles gambiae. Insect Biochem. Mol. Biol. 2012, 42, 674-682. [CrossRef] [PubMed]

57. Yang, X.; Yin, Q.; Xu, Y.; Li, X.; Sun, Y.; Ma, L.; Zhou, D.; Shen, B. Molecular and physiological characterization of the chitin synthase B gene isolated from Culex pipiens pallens (Diptera: Culicidae). Parasites Vectors 2019, 12, 614. [CrossRef] [PubMed]

58. Wang, Z.; Yang, H.; Zhou, C.; Yang, W.J.; Jin, D.C.; Long, G.Y. Molecular cloning, expression, and functional analysis of the chitin synthase 1 gene and its two alternative splicing variants in the white-backed planthopper, Sogatella furcifera (Hemiptera: Delphacidae). Sci. Rep. 2019, 9, 1087. [CrossRef]

59. Chen, L.; Yang, W.-J.; Cong, L.; Xu, K.-K.; Wang, J.-J. Molecular Cloning, Characterization and mRNA Expression of a Chitin Synthase 2 Gene from the Oriental Fruit Fly, Bactrocera dorsalis (Diptera: Tephritidae). Int. J. Mol. Sci. 2013, 14, 17055-17072. [CrossRef]

60. Shi, J.F.; Mu, L.L.; Chen, X.; Guo, W.C.; Li, G.Q. RNA interference of chitin synthase genes inhibits chitin biosynthesis and affects larval performance in Leptinotarsa decemlineata (Say). Int. J. Biol. Sci. 2016, 12, 1319-1331. [CrossRef]

61. Chen, X.; Yang, X.; Senthil Kumar, N.; Tang, B.; Sun, X.; Qiu, X.; Hu, J.; Zhang, W. The class A chitin synthase gene of Spodoptera exigua: Molecular cloning and expression patterns. Insect Biochem. Mol. Biol. 2007, 37, 409-417. [CrossRef] [PubMed]

62. Kumar, N.S.; Tang, B.; Chen, X.; Tian, H.; Zhang, W. Molecular cloning, expression pattern and comparative analysis of chitin synthase gene B in Spodoptera exigua. Comp. Biochem. Physiol. B Biochem. Mol. Biol. 2008, 149, 447-453. [CrossRef] [PubMed]

63. Qu, M.; Liu, T.; Yang, J.; Yang, Q. The gene, expression pattern and subcellular localization of chitin synthase B from the insect Ostrinia furnacalis. Biochem. Biophys. Res. Commun. 2011, 404, 302-307. [CrossRef] [PubMed]

64. Yang, W.; Xu, K.; Cong, L.; Wang, J. Identification, mRNA expression, and functional analysis of chitin synthase 1 gene and its two alternative splicing variants in oriental fruit fly, Bactrocera dorsalis. Int. J. Biol. Sci. 2013, 9, 331-342. [CrossRef] [PubMed]

65. Attardo, G.M.; Hansen, I.A.; Raikhel, A.S. Nutritional regulation of vitellogenesis in mosquitoes: Implications for anautogeny. Insect Biochem. Mol. Biol. 2005, 35, 661-675. [CrossRef] 
66. Kvamme, B.O.; Skern, R.; Frost, P.; Nilsen, F. Molecular characterisation of five trypsin-like peptidase transcripts from the salmon louse (Lepeophtheirus salmonis) intestine. Int. J. Parasitol. 2004, 34, 823-832. [CrossRef]

67. Bansal, R.; Rouf Mian, M.a.; Mittapalli, O.; Michel, A.P. Characterization of a chitin synthase encoding gene and effect of diflubenzuron in soybean aphid, aphis glycines. Int. J. Biol. Sci. 2012, 8, 1323-1334. [CrossRef]

68. Ostrowski, S.; Dierick, H.A.; Bejsovec, A. Genetic control of cuticle formation during embryonic development of Drosophila melanogaster. Genet. Soc. Am. 2002, 161, 171-182. 